\title{
Homeostatic Control of Sensory Output in Basal Vomeronasal Neurons: Activity-Dependent Expression of Ether-à-Go-Go-Related Gene Potassium Channels
}

\author{
Silke Hagendorf, Daniela Fluegge, Corinna Engelhardt, and Marc Spehr \\ Department of Cellular Physiology, Ruhr University, D-44780 Bochum, Germany
}

\begin{abstract}
Conspecific chemosensory communication controls a broad range of social and sexual behaviors. In most mammals, social chemosignals are predominantly detected by sensory neurons of a specialized olfactory subsystem, the vomeronasal organ (VNO). The behavioral relevance of social chemosignaling puts high demands on the accuracy and dynamic range of the underlying transduction mechanisms. However, the physiological concepts implemented to ensure faithful transmission of social information remain widely unknown. Here, we show that sensory neurons in the basal layer of the mouse VNO dynamically control their input-output relationship by activitydependent regulation of $\mathrm{K}^{+}$channel gene expression. Using large-scale expression profiling, immunochemistry, and electrophysiology, we provide molecular and functional evidence for a role of ether-à-go-go-related gene (ERG) $\mathrm{K}^{+}$channels as key determinants of cellular excitability. Our findings indicate that an increase in ERG channel expression extends the dynamic range of the stimulus-response function in basal vomeronasal sensory neurons. This novel mechanism of homeostatic plasticity in the periphery of the accessory olfactory system is ideally suited to adjust VNO neurons to a target output range in a layer-specific and use-dependent manner.
\end{abstract}

Key words: chemodetection; vomeronasal organ; intrinsic plasticity; sensory neuron; signaling; $\mathrm{K}^{+}$channels

\section{Introduction}

Mammals have evolved a number of distinct olfactory subsystems (Firestein, 2001; Zufall and Munger, 2001; Ache and Young, 2005; Breer et al., 2006). Among those, the accessory olfactory system and its peripheral sensory structure, the vomeronasal organ (VNO), play a critical role in detecting semiochemicals that control conspecific social behavior (Halpern and Martinez-Marcos, 2003). In rodents, apical vomeronasal sensory neurons (VSNs) express members of the V1R receptor family, whereas VSNs of the basal layer express V2R receptors (Mombaerts, 2004; Rodriguez, 2004). These receptors are thought to detect pheromonal cues that show immense structural diversity ranging from small volatile molecules (Restrepo et al., 2006) and sulfated steroids (Nodari et al., 2008) to complex peptides (Leinders-Zufall et al., 2004; Kimoto et al., 2005) and proteins (Chamero et al., 2007).

Semiochemicals trigger profound changes in endocrine status and initiate genetically preprogrammed behaviors (Brennan and

\footnotetext{
Received Aug. 2, 2008; revised Nov. 21, 2008; accepted Nov. 26, 2008.

M.S. was supported by grants from the Deutsche Forschungsgemeinschaft (SP724/2-1, Emmy Noether Program) and the Mercator Foundation. We thank L. Klein-Hitpass for performing microarray experiments and analyses, $\mathrm{H}$ Bartel for excellent technical assistance, and J. Spehr for help in figure preparation. We are indebted to R. Tirindelli for providing the V2R2 antibody and to $H$. Hatt for access to technical resources. We are grateful to E. M. Neuhaus, $H$. Benecke, and R. Dooley for valuable advice on immunoblotting and to G. Gisselmann and J. Gerkrath for helpful information on molecular methods. We also thank H. Hatt, E. M. Neuhaus, and J. Spehr for critical comments on this manuscript.

Correspondence should be addressed to Dr. Marc Spehr, Department of Cellular Physiology, Ruhr University Bochum, Universitaetsstrasse 150, D-44780 Bochum, Germany. E-mail: marc.spehr@rub.de. D0I:10.1523/JNEUROSCI.3656-08.2009

Copyright $\odot 2009$ Society for Neuroscience $\quad$ 0270-6474/09/290206-16\$15.00/0
}

Zufall, 2006). To ensure faithful transduction of such biologically relevant information, the dynamic range of VSN input-output relationships needs to be constantly adjusted within meaningful firing rate limits. Neurons achieve such homeostatic plasticity by balancing ionic conductances via compensatory feedback in an activity-dependent manner (Turrigiano, 1999; West et al., 2001; Zhang and Linden, 2003). In this context, modulation of $\mathrm{K}^{+}$ channel expression represents a key molecular mechanism to regulate neuronal input-output relationships (Zhang and Linden, 2003).

The ether-à-go-go-related gene (ERG) channels represent a unique $\mathrm{K}^{+}$channel subfamily that exhibits distinct gating and pharmacological properties (Schwarz and Bauer, 2004). In mice, the ERG subfamily is composed of three members [mERG1-3 (Warmke and Ganetzky, 1994; Shi et al., 1997)] with two splice variants of mERG1 [mERG1a and mERG1b (Lees-Miller et al., 1997; London et al., 1997)]. So far, most studies have focused on hERG, the human homolog of mERG1, which is a key mediator of cardiac action potential (AP) repolarization. Inherited hERG mutations cause long QT syndrome 2, a lethal arrhythmic disorder (Curran et al., 1995; Sanguinetti et al., 1995; Nerbonne and Kass, 2005). In neurons, however, the physiological roles of ERG channels are poorly understood (Sanguinetti and TristaniFirouzi, 2006). Overlapping subunit expression in central neuron somata (Guasti et al., 2005) suggests that endogenous ERG channels form heterotetramers, likely coassembling with promiscuous $\beta$-subunits such as MinK-related peptides (MiRPs). A characteristic feature of ERG channels is their unconventional gating. Activated during depolarization, fast inactivation and a combi- 
nation of fast recovery from inactivation and relatively slow deactivation during repolarization underlie inward net ion movement (Schwarz and Bauer, 2004). However, gating properties vary substantially between endogenous and heterologously expressed ERG channels and between subunits (Pond and Nerbonne, 2001; Hirdes et al., 2005). So far, neuronal ERG currents have been described in cerebellar Purkinje neurons (Sacco et al., 2003) and ventral horn interneurons (Furlan et al., 2007).

Here, we analyzed activity-dependent $\mathrm{K}^{+}$channel expression in the mouse VNO. Compared with stimulus-deprived animals, ERG1 channel expression is upregulated in mice chronically exposed to pheromonal cues. We show that basal neurons coexpress ERG1 and ERG3 and exhibit a fast ERG-mediated $\mathrm{K}^{+}$current that is significantly reduced after stimulus deprivation. We demonstrate a function of ERG-mediated currents in VSN spike repolarization and show impaired AP firing after ERG channel inhibition. Together, our findings support a concept of homeostatic plasticity in the accessory olfactory system based on usedependent regulation of ERG channel expression. This mechanism is ideally suited to adjust a target vomeronasal output range in a layer-specific manner.

\section{Materials and Methods}

Solutions and chemicals. For tissue preparation and electrophysiological recordings, the following solutions were used: (1) HEPES-buffered extracellular solution $\left(\mathrm{S}_{1}\right)$ containing (in $\mathrm{mM}$ ) $145 \mathrm{NaCl}, 5 \mathrm{KCl}, 1 \mathrm{CaCl}_{2}, 1$ $\mathrm{MgCl}_{2}, 10$ HEPES, pH 7.3 (adjusted with $\mathrm{NaOH}$ ), osmolarity of 300 mOsm (adjusted with glucose); (2) bicarbonate-buffered oxygenated $\left(95 \% \mathrm{O}_{2} / 5 \% \mathrm{CO}_{2}\right.$ ) extracellular solution $\left(\mathrm{S}_{2}\right)$ containing (in $\left.\mathrm{mM}\right) 120$ $\mathrm{NaCl}, 25 \mathrm{NaHCO}_{3}, 5 \mathrm{KCl}, 1 \mathrm{MgSO}_{4}, 1 \mathrm{CaCl}_{2}, 5 \mathrm{BES}$ ( $N, N$-bis[2hydroxyethyl]-2-aminoethansulfonic acid), $\mathrm{pH} 7.3$, osmolarity of 300 mOsm; (3) elevated potassium extracellular solution $\left(\mathrm{S}_{3}\right)$ containing (in mм) $110 \mathrm{NaCl}, 40 \mathrm{KCl}, 1 \mathrm{MgCl}_{2}, 1.5 \mathrm{CaCl}_{2}, 5 \mathrm{EGTA}\left(110 \mathrm{~nm}\right.$ free $\mathrm{Ca}^{2+}$ ), 10 HEPES, tetrodotoxin (TTX; $0.5 \mu \mathrm{M}$ ), $\mathrm{pH} 7.3$, osmolarity of 300 mOsm; (4) low $\mathrm{Ca}^{2+}$ solution $\left(\mathrm{S}_{4}\right)$ for enzymatic tissue digestion containing (in mM) $135 \mathrm{NaCl}, 5$ EGTA, $4.25 \mathrm{CaCl}_{2}, 5 \mathrm{KCl}, 10 \mathrm{NaOH}, 1$ $\mathrm{MgCl}_{2}, 10$ HEPES, pH 7.3, osmolarity of 300 mOsm; and (5) HEPESbuffered pipette solution containing (in mM) $143 \mathrm{KCl}, 10$ HEPES, 2 $\mathrm{KOH}, 0.3 \mathrm{CaCl}_{2}, 1$ EGTA (110 nm free $\mathrm{Ca}^{2+}$ ), $1 \mathrm{MgATP}, 0.5 \mathrm{NaGTP}, \mathrm{pH}$ 7.1 (adjusted with $\mathrm{KOH}$ ), osmolarity of $290 \mathrm{mOsm}$. If not stated otherwise, all chemicals were purchased from Sigma. Free $\mathrm{Ca}^{2+}$ concentrations were calculated using WEBMAXC STANDARD (available at www.stanford.edu/ $\sim$ cpatton/maxc.html).

To ensure full, rapid isolation of ERG channel-mediated potassium currents in voltage-clamp recordings, saturating concentrations of the methanesulfonanilide drug E-4031 $(10 \mu \mathrm{M})$ or the recombinant peptide rErgtoxin-1 (100 nM; Alomone Labs) were applied in $\mathrm{S}_{3}$. Subunit-specific mERG1 currents were isolated using the recombinant peptide $\mathrm{rBeKm}-1$ at a concentration (100 nM; Alomone Labs) that completely blocks mERG1 without affecting mERG3 (Restano-Cassulini et al., 2006).

Animals. All animal procedures were in compliance with the European Union legislation on the protection of animals used for experimental purposes (Directive 86/609/EEC) and with recommendations put forward by the Federation of European Laboratory Animal Science Associations. Mice used for experiments shown in Figures $2-6 a-f$ and supplemental Figures $1 a-d, 2,3 a-d$, and 4 (available at www.jneurosci.org as supplemental material), either wild-type C57BL/6 mice or gene-targeted mice in which all mature VSNs can be visualized based on homozygous expression of green fluorescent protein (GFP) under the control of the regulatory sequences of the olfactory marker protein (omp) gene (OMPGFP) (Potter et al., 2001), were housed in groups of both sexes at room temperature on a $12 \mathrm{~h}$ light/dark cycle with food and water available ad libitum. If not stated otherwise, experiments used young adults of either sex. We did not observe any obvious differences between males and females in neither electrophysiological recordings nor molecular or immunochemical experiments.

VNO preparation. Mice were killed by $\mathrm{CO}_{2}$ asphyxiation and decapi- tation using sharp surgical scissors, following the "guidelines for euthanasia of rodents using $\mathrm{CO}_{2}$ " recently issued by the National Institutes of Health Office of Laboratory Animal Welfare. The VNO was dissected in oxygenated, ice-cold $S_{1}$ as described previously (Leinders-Zufall et al., 2000; Spehr et al., 2006). For preparations of acute slices, the intact VNO was embedded in $4 \%$ low-gelling-temperature agarose, and coronal slices $(300 \mu \mathrm{m})$ were cut on a Vibratome (VT1000S; Leica Microsystems). Slices were transferred to a submerged $\left(S_{2}\right)$, chilled, and oxygenated storage chamber until use.

RNA extraction and reverse transcription-PCR. C57BL/6 mice were killed as described (see above, VNO preparation). Brain, heart, and VNO tissue samples were removed and immediately frozen in liquid nitrogen. RNA was extracted and purified from tissues and cultured LNCaP cells using the RNeasy Mini kit (Qiagen) and DNase digestion. RNA from each sample was quantified using the NanoDrop ND-1000 UV-Vis spectrophotometer (Thermo Fisher Scientific). Five micrograms of total RNA served as a template for oligo-dT- and random hexamer-primed first-strand cDNA synthesis using Moloney murine leukemia virus reverse transcriptase (RT; Invitrogen). PCR was performed in a Mastercycler ep gradient S (Eppendorf) using TaqDNA polymerase (Promega), $1.5 \mathrm{mM} \mathrm{MgCl}_{2}, 0.2 \mathrm{~mm}$ of each dNTP, and $100 \mathrm{pm}$ forward/reverse targetspecific oligonucleotide primers. Cycling parameters consisted of an initial denaturation step at $94^{\circ} \mathrm{C}$ for $5 \mathrm{~min}$, followed by 35 cycles ( $30 \mathrm{~s} \mathrm{each}$ ) of $94^{\circ} \mathrm{C}$ (step 1), primer pair-specific annealing temperature (step 2), and $72^{\circ} \mathrm{C}$ (step 3), and completed by a final extension at $72^{\circ} \mathrm{C}$ for $5 \mathrm{~min}$. The following primer sequences and annealing temperatures were used to amplify target cDNA: ERG1a, 5'-ATGCCGGTGCGGAGGGGCCAC-3' (fwd1)/5' -TAGAAGGCGATCTCCACTTTG-3' (rev1)/temperature $(\mathrm{T})=55^{\circ} \mathrm{C}$; ERG1b, $5^{\prime}$-ATGGCGATTCCAACCGGGAAG-3' $(\mathrm{fwd} 1) / 5^{\prime}$-ACAGTCAGGGGCTTGGGACCC-3' $(\mathrm{rev1}) / \mathrm{T}=60^{\circ} \mathrm{C}$; ERG2, 5'-ATGCCAGTCCGCAGGGGCCA-3' (fwd1)/5' -CATCCACCAGGCAGCGGAAGC-3' $(\mathrm{rev} 1) / \mathrm{T}=58^{\circ} \mathrm{C}$; ERG3, 5' -ATGCCTGTTCGCAGGGGGCAT-3' (fwd1)/5' -CTGGGATTATGTGAGTGTTAC-3' $(\operatorname{rev} 1) / \mathrm{T}=54^{\circ} \mathrm{C} ;$ MiRP2. $5^{\prime}$-ATGGAGACTTCCAACGGGAC-3' $(\mathrm{fwd} 1) / 5^{\prime}$-GACCTGGTACATGAGCCTCC-3' $(\mathrm{rev} 1) / \mathrm{T}=56^{\circ} \mathrm{C}$. Primers were designed using Clone Manager software (Sci-Ed Software). The annealing temperature for each primer pair was calculated from their individual G/C and A/T content. PCR products were separated by electrophoresis in $1.5 \%$ agarose gels containing ethidium bromide $(0.5 \mu \mathrm{g} /$ $\mathrm{ml}$ ), followed by a second amplification to check for weak or false amplification. For this nested PCR, $0.5 \mu \mathrm{l}$ of the purified initial product served as a template, and the following primer sequences and annealing temperatures were used: ERG1a, 5'-TCGCGCCGCAGAACACCTTCC-3' $(\mathrm{fwd} 2) / 5^{\prime}$-CTCCTCTGCGCCCAGCAGGGC-3' $(\mathrm{rev} 2) / \mathrm{T}=63^{\circ} \mathrm{C} ; \mathrm{ERG} 1 \mathrm{~b}, 5^{\prime}$ CAGGGGCTCTGCAGCCCAGGG- $3^{\prime}$ (fwd2)/5'-CTCCTTCAGCAGGAAGGCGGC-3' $(\mathrm{rev} 2) / \mathrm{T}=62^{\circ} \mathrm{C} ;$ ERG2, $5^{\prime}$-CCAAAACACTTACTTGGACAC-3' $(\mathrm{fwd} 2) / 5^{\prime}$-CTTGCGATAGTAGAGGATGTCC-3' $(\mathrm{rev} 2) / \mathrm{T}=$ $58^{\circ} \mathrm{C}$; ERG3, 5'-CTTCCTGGGGACCATCATACG-3' (fwd2)/5'-CTTGTGATAGTAGGTGACC-3' $(\mathrm{rev} 2) / \mathrm{T}=56^{\circ} \mathrm{C} ; \mathrm{MiRP2}, 5^{\prime}$-TCAGATCATAGACACACGGTTC- $3^{\prime}$ (fwd 2$) / 5^{\prime}$-GATGTACACATGATAGGGGTC-3' (rev2) $/ \mathrm{T}=52^{\circ} \mathrm{C}$. The identity of PCR products was confirmed by sequencing using the 3130xl Genetic Analyzer and BigDye Terminator version 3.1 Cycle Sequencing kit (Applied Biosystems).

Expression profiling. Oligonucleotide microarray analyses were performed for eight individual RNA samples (four arrays from RNA of pheromone-stimulated mice [(experimental group/(exp)], four arrays of RNA from stimulus-deprived animals [(control group)/(contr)], each containing pooled vomeronasal RNA of five singly housed C57BL/6 male mice. Total RNA was isolated from VNO whole-organ preparations using Trizol reagent (Invitrogen) and the RNeasy Mini kit (Qiagen) according to the manufacturer's instructions. The quality (2100 bioanalyzer, RNA 6000 Pico LabChip; Agilent) and quantity (NanoDrop ND1000 ) of this starting RNA were analyzed, and samples were only processed if the quality was satisfactory as indicated by the absence of degradation of ribosomal RNA ( $28 \mathrm{~S} / 18 \mathrm{~S}$ rRNA ratios $\sim 2)$. Synthesis of double-stranded cDNA, generation of biotinylated cRNA, hybridization to Mouse Genome430_2.0 arrays (Affymetrix), washing (GeneChip Fluidics Station 400), staining, and scanning of the arrays (GeneChip Scanner3000) were done as recommended (Expression_s2_manual; Af- 
fymetrix). RNA quality was additionally controlled by hybridization to Affymetrix Test 3 chips.

Signal intensities, detection calls (present, absent, and marginal), and pairwise analyses of expression changes between experimental and control arrays were determined from processed array images using the GCOS1.4 software (Affymetrix), exported as Microsoft Excel spreadsheets, and processed using the Significance Analysis of Microarrays (SAM) software tool (available at http://www-stat.stanford.edu/ tibs/ SAM). GCOS1.4 software was used to calculate the average noise $(2.55 \pm$ $0.1)$, the average background signal level (54.62 \pm 0.84$)$, the average percentages of "present" and "absent" calls (present, $54.96 \pm 0.72 \%$; absent, $43.28 \pm 0.75 \%)$, the average signal level for all probe sets $(1364.98 \pm 17)$, the average actin $3^{\prime} / 5^{\prime}$ signal ratio $(1.41 \pm 0.03)$, and the average glyceraldehydes-3-phosphate dehydrogenase (GAPDH) 3'/5' signal ratio $(0.98 \pm 0.04)$. To monitor target labeling, poly-A controls (GeneChip Poly-A RNA Control kit) were spiked into RNA samples and called present on all arrays. The detailed quality report is available for download (www.rub.de/signaling). One array from stimulus-deprived controls did not meet conservative quality standards and was thus eliminated from additional analysis resulting in a total of seven replicates. A scaling across all probe sets of a given array to a target intensity of 1000 was included to compensate for variations in the amount and quality of the cRNA samples and other experimental variables. Transcripts were defined as differentially expressed between the stimulated mice and the odor-deprived controls if signal intensities met the following criteria: (1) the gene had to be consistently detected in at least $100 \%$ of the samples of either group; and (2) either pairwise statistical analyses of expression changes using a Mann-Whitney test for independent samples showed a $p$ value of $p<0.05$ or random overlap matrix analysis of multiple pairwise comparisons (exp/contr vs contr/contr; under both conditions each transcript is compared 12 times) showed regulated expression only in exp/contr comparisons.

Immunocytochemistry. The VNO was dissected as described (see above, VNO preparation). For preparation of cryosections, the VNO was fixed for $2 \mathrm{~h}$ in $4 \%$ paraformaldehyde in PBS $(150 \mathrm{~mm}$ Tris- $\mathrm{HCl}$ and 50 $\mathrm{mm} \mathrm{NaCl}, \mathrm{pH} 7.4$ ) at $4^{\circ} \mathrm{C}$, decalcified overnight in $0.5 \mathrm{M}$ EDTA, and cryoprotected in PBS containing 30\% sucrose. The dehydrated VNO was embedded in Tissue Freezing Medium (Leica Microsystems) and sectioned at $25 \mu \mathrm{m}$ on a cryostat (Leica Microsystems). The same protocol was used for sagittal cryosections of the cerebellum.

For single neuron immunostainings, the $\mathrm{VNO}$ was minced and digested in $0.19 \mathrm{mg} / \mathrm{ml}$ papain and $1 \mathrm{U} / \mathrm{ml}$ DNase (Promega) in $\mathrm{S}_{4}$ for 20 min at $37^{\circ} \mathrm{C}$. The tissue was then transferred to $S_{1}$ solution and gently triturated using fire-polished glass pipettes saturated with bovine serum albumin (BSA). Nondissociated cells were removed from the cell suspension using BD Falcon Cell Strainer nylon meshes $(70 \mu \mathrm{m}$ pore diameter; Becton Dickinson). Dissociated VSNs were transferred to concanavalin A-coated glass-bottom dishes. After $30 \mathrm{~min}\left(4^{\circ} \mathrm{C}\right)$, VSNs had attached to the bottom of the dishes and were then fixed for $30 \mathrm{~min}$ in $4 \%$ paraformaldehyde in $\mathrm{PBS}\left(4^{\circ} \mathrm{C}\right)$.

The following antibodies were used in this study: primary antisera include rabbit anti-KCNH2/anti-KCNH6/anti-KCNH7/anti-KCNE3 (ERG1/ERG2/ERG3/MiRP2; Alomone Labs), rabbit anti-V2R2 (kindly provided by Dr. R. Tirindelli, University of Parma, Parma, Italy), rabbit anti-PDE4A (Novus Biologicals), and rabbit anti-KCNH2 (Santa Cruz Biotechnology). Goat anti-rabbit Alexa Fluor 488, 532, and 633 (Invitrogen) were used as secondary antibodies. Unless indicated otherwise, blocking and staining procedures were identical for both dissociated VSNs and VNO cryosections. Blocking was performed for $1 \mathrm{~h}$ (cryosections) or $30 \mathrm{~min}$ (dissociated VSNs), respectively, in PBS containing 2\% goat serum, $1 \%$ gelatin, and $0.2 \%$ Triton X-100 (blocking solution). Cells and sections were then incubated for $1 \mathrm{~h}$ (room temperature; dissociated VSNs) or overnight $\left(4^{\circ} \mathrm{C}\right.$; cryosections) with affinity-purified primary antibody sera (1:500, ERG1/MiRP2/V2R2/PDE4A; 1:250, ERG2/ERG3) in blocking solution, washed in PBS containing $0.05 \%$ Triton X-100 (three times for $10 \mathrm{~min}$, one time for $30 \mathrm{~min}$ ), and incubated for $1 \mathrm{~h}$ (sections) or $30 \mathrm{~min}$ (VSNs) with Alexa Fluor secondary antibodies (1: 500; Invitrogen). Excess antibodies were removed by washing in PBS containing $0.05 \%$ Triton X-100 (three times for $10 \mathrm{~min}$, one time for 30 min). For multilabeling of sections with primary antibodies from the same host species, we adopted a published protocol that uses Fab fragments for blocking and labeling (Leinders-Zufall et al., 2004). To control for nonspecific staining, experiments in which the primary antibodies were omitted were performed in parallel with each procedure.

Fluorescent images were taken using an upright scanning confocal microscope (LSM510-Meta; Zeiss) equipped with a $10 \times$ [water immersion, numerical aperture (n.a.) 0.30] and $40 \times$ (water immersion, n.a. 0.80 ) objective. To eliminate cross talk between labels, the multitracking configuration was applied. Endogenously expressed GFP, as well as Alexa Fluor 488, was excited using the $488 \mathrm{~nm}$ line of an argon laser, and emitted fluorescence was captured using a bandpass filter (500-550IR $\mathrm{nm})$. Alexa Fluor 532 and 633 were excited using the 543 and $633 \mathrm{~nm}$ line of a helium/neon laser, respectively, and fluorescence was captured using a long-pass filter ( $560 \mathrm{~nm}$; Alexa Fluor 532) or a bandpass filter (650-710 $\mathrm{nm}$; Alexa Fluor 633). In some experiments, cell nuclei were stained by brief incubation with DAPI (4',6-diamidino-2-phenylindole) (Invitrogen). In such cases, a Ti:sapphire laser (Mai Tai; Spectra Physics), running at $800 \mathrm{~nm}$, was used as a light source for multiphoton excitation. Digital images were uniformly adjusted for brightness and contrast using Adobe Photoshop CS3 (Adobe Systems).

Immunoblotting. VNOs and control cells and tissues were homogenized in ice-cold $S_{1}$ lysis buffer in the presence of Complete Mini protease inhibitor cocktail tablets (Roche) using a Dounce homogenizer. All membrane preparation procedures were performed at $4^{\circ} \mathrm{C}$. The homogenate was briefly sonicated and centrifuged for $10 \mathrm{~min}(1000 \times g)$. The supernatant was collected and ultracentrifuged $(2 \mathrm{~h}, 49,000 \times g)$. The pellet was resuspended in lysis buffer, and protein concentration was determined using a Bradford protein assay kit (Bio-Rad) standardized on BSA. Protein samples were solubilized in Laemmli buffer (20\% glycerol, $4 \%$ SDS, $125 \mathrm{~mm}$ Tris- $\mathrm{HCl}$, and $0.02 \%$ bromphenol blue, $\mathrm{pH} 6.8$ ) and DTT $(5 \%)$, and equal amounts of protein $(35 \mu \mathrm{g})$ were fractionated by size using $8-15 \%(\mathrm{w} / \mathrm{v})$ denaturing SDS-PAGE. Separated proteins were transferred to Immobilon Transfer Membranes (Millipore) or nitrocellulose membrane (Protran; Whatman) using a Criterion Blotter wetblotting system (Bio-Rad). Membranes were washed, stained with Ponceau $\mathrm{S}$ to control for protein transfer, and again washed with TBST (150 mм Tris-HCl, $50 \mathrm{~mm} \mathrm{NaCl}$, and $0.1 \%$ Tween 20, $\mathrm{pH} 7.4$ ). Blocking was performed in 5\% nonfat dry milk/TBST (Bio-Rad) for $1 \mathrm{~h}$. Blots were then incubated overnight at $4^{\circ} \mathrm{C}$ in $3 \%$ nonfat dry milk/TBST with affinity-purified polyclonal rabbit antibodies against human $\mathrm{KCNH} 2$ (anti-ERG1; 1:250) and human KCNE3 (anti-MiRP2; 1:750). Membranes were then washed (four times for $15 \mathrm{~min}$ ) in TBST and incubated at room temperature with horseradish peroxidase-conjugated goat antirabbit IgG (1 h; 1:10,000; Bio-Rad) in 3\% nonfat dry milk/TBST. Blots were again washed in TBST (four times for $15 \mathrm{~min}$ ), and antibody binding was detected using ECL Plus Western Blotting Reagent (GE Healthcare). To control for equal protein loading per lane, membranes were stripped using Restore Western Blot Stripping Buffer (Pierce), washed with TBST, blocked for $1 \mathrm{~h}$ in 5\% nonfat dry milk/TBST, and reprobed for $1 \mathrm{~h}$ in 3\% nonfat dry milk/TBST for expression of GAPDH and $\beta$-tubulin, respectively, using a mouse monoclonal anti-GAPDH antibody $(1: 30,000 ; \mathrm{Abcam})$ and a rabbit polyclonal anti- $\beta$-tubulin antibody (1:2,500; Abcam). Blots were washed in TBST (four times for $15 \mathrm{~min}$ ) and incubated with horseradish peroxidase-conjugated goat anti-rabbit IgG or anti-mouse IgG ( $1 \mathrm{~h} ; 1: 10,000$; Bio-Rad), respectively. After washing in TBST (four times for $15 \mathrm{~min}$ ), antibody binding was detected as described. After background correction, semiquantitative densitometry measurements of scanned immunoblot band intensities within standard-size rectangular regions of interest were performed using MetaMorph 7.1 imaging software (Universal Imaging Corporation). Calibrated pixel intensities were transformed into an optical density (OD) value according to $\mathrm{OD}=\log 10[255 /(255$ - gray value $)]$. The OD values of ERG1 and MiRP2 bands were normalized to their associated GAPDH and/or $\beta$-tubulin controls to compensate for variations in loading and transference.

Electrophysiology. For electrophysiological recordings, VNO slices were transferred to a recording chamber (Slice Mini Chamber; Luigs \& Neumann) and visualized using a Leica DM LFSA (Leica Microsystems) 
fixed-stage upright video microscope equipped with apochromatic water-immersion objectives and infrared-optimized differential interference contrast (DIC) optics. Slices were anchored via stainless steel wires with $0.1-\mathrm{mm}$-thick lycra threads and continuously superfused with oxygenated solution $S_{2}(\sim 3 \mathrm{ml} / \mathrm{min}$; gravity flow) at room temperature. Patch pipettes (5-7 M $\Omega$ ) were pulled from borosilicate glass capillaries with filament and fire-polished ends $(1.50 \mathrm{~mm}$ outer diameter, $0.86 \mathrm{~mm}$ inner diameter; Science Products) on a PC-10 vertical two-step micropipette puller (Narishige Instruments) and fire polished using a MF-830 Microforge (Narishige Instruments). Pipettes were advanced toward individual neurons under optical control applying positive backpressure. After a $G \Omega$ seal was obtained, gentle negative pressure was applied to establish the whole-cell configuration. An EPC-10 amplifier controlled by Patchmaster 2.20 software (HEKA Elektronik) was used for data acquisition. Both pipette $\left(C_{\text {fast }}\right)$ and cell membrane $\left(C_{\text {slow }}\right)$ capacitance, as well as series resistance $\left(R_{\mathrm{s}}\right.$; up to $85 \%$ correction, $\left.10 \mu \mathrm{s} \mathrm{lag}\right)$, were monitored and automatically compensated throughout the experiment. Measured $C_{\text {slow }}$ values served as an approximation of the cell-surface area for normalization of current amplitudes (i.e., current density). Only neurons exhibiting stable access resistances (change $<10 \%$ ) were used for analysis. Theoretical liquid junction potentials were calculated using JPCalcW software (Barry, 1994) and automatically corrected on-line.

In voltage-clamp experiments, leak currents were subtracted using a $\mathrm{P} /-4$ procedure. Signals were low-pass filtered (analog three- and fourpole Bessel filters in series) with an effective corner frequency $(-3 \mathrm{~dB})$ automatically adjusted to one-fifth to one-third of the sampling rate (5-20 kHz, depending on protocol). Because ERG channel gating characteristics result in effective inward rectification and ERG conductance is directly related to the external $\mathrm{K}^{+}$concentration $\left[\mathrm{K}^{+}\right]_{\mathrm{o}}, \mathrm{K}^{+}$currents $\left(I_{\mathrm{K}(\mathrm{ERG})}\right)$ were identified and studied with a standard high $\left[\mathrm{K}^{+}\right]_{\mathrm{o}}$ extracellular solution $\left(\mathrm{S}_{3}\right.$; calculated Nernst equilibrium potential for $\mathrm{K}^{+}$, $-32.5 \mathrm{mV}$ ) (Sacco et al., 2003; Furlan et al., 2007; Hirdes et al., 2005), balanced $\left[\mathrm{Ca}^{2+}\right]_{\mathrm{i}} /\left[\mathrm{Ca}^{2+}\right]_{\mathrm{o}}$, and blocked voltage-gated $\mathrm{Na}^{+}$channels (TTX; $0.5 \mu \mathrm{M}$ ). This treatment, however, demanded that VSNs were analyzed on a one-recording-per-slice basis. Solution exchange $\left(\mathrm{S}_{2}\right.$ to $\left.\mathrm{S}_{3}\right)$ after break-in and application of drug-containing solutions was achieved by a custom-made, pressure-driven focal application device consisting of a software-controlled valve bank connected to a "perfusion pencil." Between recordings, cells were kept at a holding potential $\left(V_{\text {hold }}\right)$ of -80 $\mathrm{mV}$. Individual voltage-step protocols are described in Results. To analyze $I_{\mathrm{K}(\mathrm{ERG})}$ during AP discharge, prerecorded APs elicited by positive current injections were used as the command waveform (AP clamp).

In current-clamp experiments, slices were perfused with extracellular solution $\mathrm{S}_{2}$. The resting membrane potential was measured directly after obtaining access to the cell interior using the software-controlled "gentle switch" of the EPC-10 patch-clamp amplifier. The membrane potential was then set to $-75 \mathrm{mV}$ by injecting a constant holding current $( \pm 3 \mathrm{pA}$ or less). AP discharge patterns were investigated by delivering depolarizing current injections of variable duration and intensity.

Data analysis. Statistical analysis of paired or unpaired two-sample distributions was performed as dictated by data distribution. Results of individual serial randomness tests for normally distributed random samples and subsequent $F$ tests for equal variances determined the use of either $t$ tests or Wilcoxon rank tests. If not stated otherwise, a $p$ value $<0.01$ was considered significant, and results are presented as means \pm SEM.

Electrophysiological data were analyzed off-line using FitMaster 2.20 (HEKA Elektronik), IGOR Pro 6.03A (WaveMetrics), and Excel (Microsoft) software. Activation curves were fitted by the Boltzmann equation $I / I_{\max }=I_{\max } /\left\{1+\exp \left[\left(V_{1 / 2}-V\right) / k\right]\right\}$, where $V_{1 / 2}$ is the voltage that produces half-maximal activation and $k$ is the slope factor. Decay time constants $(\tau)$ for current deactivation were calculated by fitting individual traces during a fixed time period (2-25 $\mathrm{ms}$ after repolarization) to monoexponential functions $I_{(\mathrm{t})}=I_{1}[\exp (-t / \tau)]+I_{0}$, where $I_{(\mathrm{t})}$ is the current at time $t, I_{1}$ is the initial amplitude, $\tau$ is the decay time constant, and $I_{0}$ is the residual current. Event detection and spike analysis was performed using the Neuromatic 1.86 software package (written by Jason Rothman) implemented in IGOR Pro 6.03A and MiniAnalysis software (Synaptosoft).
Three-dimensional reconstruction. In voltage- and current-clamp recordings, Alexa Fluor 488 hydrazide ( $20 \mu \mathrm{M}$; Invitrogen) was routinely added to the pipette solution for on-line in situ visualization of VSN morphology, post hoc immunocytochemical analysis, and threedimensional (3-D) reconstruction. After break-in, cells were loaded via diffusion. Whole-cell configuration was maintained for at least $20 \mathrm{~min}$ to allow for adequate dye filling. After recording, slices were immersion fixed for $30 \mathrm{~min}$ at $4^{\circ} \mathrm{C}$ in PBS containing $4 \%$ paraformaldehyde and processed for immunocytochemistry as described above. The morphology of dye-filled cells was studied using an upright scanning confocal microscope (LSM510-Meta; Zeiss) equipped as described above. For 3-D reconstruction of fluorescently labeled VSNs, axial projections of optical section stacks (0.7-1.1 $\mu \mathrm{m} \mathrm{z-step} \mathrm{intervals)} \mathrm{were} \mathrm{generated} \mathrm{as} \mathrm{transpar-}$ encies using a 3-D projection algorithm implemented in the confocal imaging software (Zeiss).

\section{Results \\ Activity-dependent expression of $\mathrm{K}^{+}$channel genes in the VNO}

In many neurons, the balance of intrinsic ionic conductances is constantly adjusted as a function of ongoing activity. One mechanism to set a target output range is regulated expression of specific $\mathrm{K}^{+}$channels (Zhang and Linden, 2003). To determine whether transcription of $\mathrm{K}^{+}$channel genes is activity regulated in the mouse VNO, we surveyed expression profiles of adult male C57BL/6 mice that had been singly housed either in an essentially odor-free environment (deprived group) or exposed to rich sources of pheromonal cues (stimulated group). Stimulation cycles $(7 \mathrm{~d})$ were composed of $6 \mathrm{~h}$ exposure to fresh male urine (2:00-8:00 P.M.), $12 \mathrm{~h}$ exposure to female-soiled bedding (8:00 P.M. to 8:00 A.M.), and an additional $6 \mathrm{~h}$ without stimulation (8:00 A.M. to 2:00 P.M.) to allow for relief from potential sensory adaptation (Fig. 1a). Vomeronasal $\mathrm{K}^{+}$channel transcription levels were compared between stimulated and deprived tissue using a total of seven Affymetrix microarrays (four experiment and three control replicates), each chip probing pooled mRNA from five animals. Applying conservative quality control and evaluation criteria (see Materials and Methods), $5 \mathrm{~K}^{+}$channel genes were found both consistently detected and differentially expressed (Fig. 1b; see supplemental Table 1, available at www. jneurosci.org as supplemental material, for a summary of results). The most pronounced changes were observed for ERG1 (upregulation) and the modulatory single transmembrane domain $\beta$-subunit MiRP2 (downregulation), which was reported to inhibit ERG1 currents when coexpressed in Xenopus oocytes (Schroeder et al., 2000). We next determined vomeronasal expression of ERG1-3 and MiRP2 by RT-PCR. Using specific primers for both ERG1 isoforms (ERG1a and ERG1b), ERG2, ERG3, and MiRP2, we detected transcripts of all genes. Transcript identity was confirmed by nested PCR (Fig. 1c) and sequencing. Bands of the appropriate size were also obtained from cerebellum (Papa et al., 2003; Guasti et al., 2005) and heart (ERG1a, ERG1b, and MiRP2) (Shi et al., 1997) but not from cultured prostate cancer cells (LNCaP).

Next, we aimed to examine activity-dependent changes in ERG1a, ERG1b, and MiRP2 expression on the protein level. In ERG1 immunoblot analyses, the antibody detects two bands at $\sim 165$ and $\sim 100 \mathrm{kDa}$ in VNO protein extracts (supplemental Fig. $1 a$, available at www.jneurosci.org as supplemental material), corresponding to $N$-glycosylated ERG1a and ERG1b (Pond et al., 2000; Hirdes et al., 2005). Equivalent bands were not detected in eye or LNCaP protein extracts. Probing blots of VNO and brain protein with an anti-MiRP2 antibody revealed bands of the expected size ( $\sim 20 \mathrm{kDa}$ ) (McCrossan et al., 2003) 
a

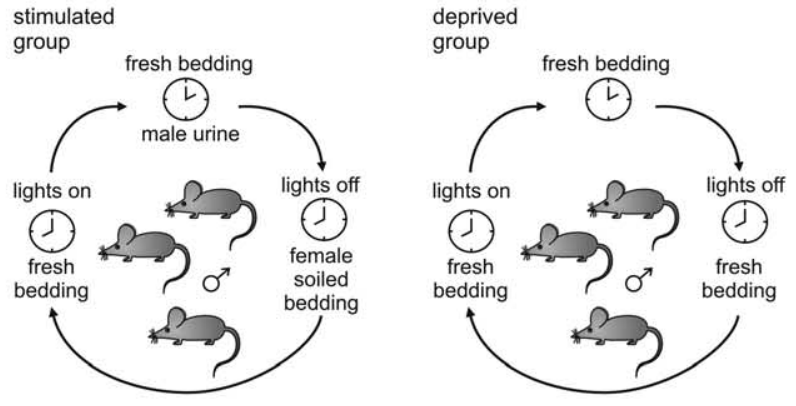

C
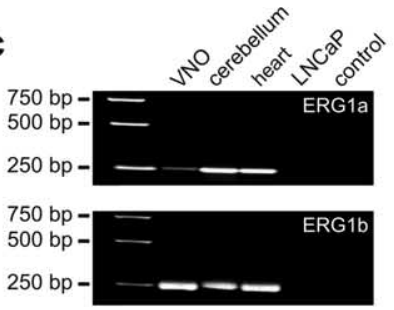

$500 \mathrm{bp}-\quad-\quad$ ERG3

$250 \mathrm{bp}$

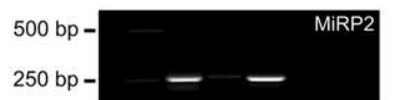

d

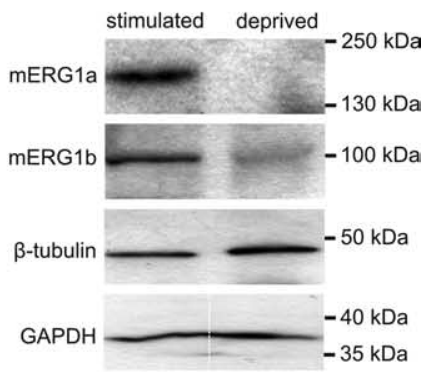

b

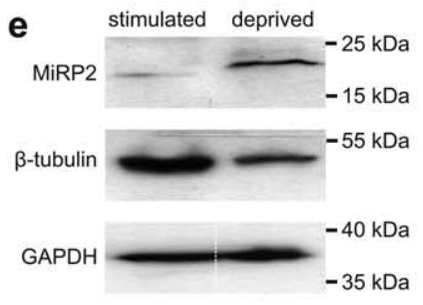

Figure 1. Activity-dependent $\mathrm{K}^{+}$channel gene expression in the VNO. $\boldsymbol{a}$, Schematic diagram illustrating the experimental strategy used for pheromone exposure (left) and stimulus deprivation (right) of singly housed C57BL/6 mice. $\boldsymbol{b}$, Differentially expressed K ${ }^{+}$channel genes in the VNO. Analysis (see Materials and Methods) of seven microarrays ( 4 stimulated/3 deprived) reveals both consistent expression (7 of 7 arrays) and significant ( $p \leq 0.029$ ) regulation of the following genes: Kcnh2 (ERG1; up), Kcna5 (up), Kcne3 (MiRP2; down), Kcna2 (down), and Kcnj16 (down). For each gene, RefSeq accession numbers, Affymetrix identifications, and average fold changes (mean \pm SEM; 12 independent comparisons) are specified. $c$, Vomeronasal transcripts of both ERG1 isoforms (ERG1a and ERG1b), ERG3, and MiRP2 are detected by RT-PCR and sequencing. Specificity is confirmed by positive [cerebellum; heart (ERG1a, ERG1b, MiRP2)] and negative [heart (ERG3); LNCaP cells] controls. No PCR product is amplified when reverse transcription is omitted (control). $\boldsymbol{d}, \boldsymbol{e}$, Representative immunoblotting experiments illustrating the regulation of ERG1 and MiRP2 protein expression. Individual blot panels ( $\boldsymbol{d}$ or $\boldsymbol{e}$ ) correspond to the same SDS-polyacrylamide gel, respectively. $\boldsymbol{d}$, Western blot analysis demonstrating increased levels of vomeronasal ERG1a/1b expression in stimulated mice versus deprived mice. Blots $(n=4)$ were additionally probed for $\beta$-tubulin and GAPDH as loading controls. $\boldsymbol{e}$, Western blots $(n=3)$ probed with MiRP2 antibody reveal downregulated protein expression in stimulated animals.

in both tissues (supplemental Fig. 1b, available at www. jneurosci.org as supplemental material). An anti-ERG3 antibody detected a single band of $\sim 105 \mathrm{kDa}$ in blots of both cerebellum and VNO (supplemental Fig. $1 c$, available at www.jneurosci.org as supplemental material). An anti-ERG2 antibody, however, stained multiple bands in the expected $100-110 \mathrm{kDa}$ range in the cerebellum but not the VNO (supplemental Fig. 1d, available at www.jneurosci.org as supplemental material), suggesting no or only marginal translation of ERG2 transcripts in vomeronasal tissue. Using the exact same stimulation/deprivation protocol as described above (Fig. 1a), pooled VNO protein from stimulated $(n=10)$ and deprived $(n=12)$ mice, respectively, was subjected to immunoblot analysis (Fig. $1 d, e$ ). $\beta$-Tubulin and GAPDH were found at constant levels in microarray experiments and thus served as loading controls. All antibodies detected distinct bands of the expected molecular size. Comparing stimulated and deprived mice, however, revealed substantial differences in band intensity for ERG1a, ERG1b $(n=4)$, and MiRP2 $(n=3)$. For stimulus-exposed animals, prominent bands were detected for ERG1a and ERG1b (Fig. 1d), whereas labeling intensity was much weaker in samples from deprived mice. An opposite regulation was observed for MiRP2 (Fig. 1e). These results were confirmed by semiquantitative densitometry measurements of scanned immunoblot band intensities (supplemental Fig. 1e). Thus, the activity-dependent regulation of $E R G$ and MiRP2 $\mathrm{K}^{+}$channel transcripts we identified by microarray profiling is effectively translated into upregulated (ERG1 isoforms) and downregulated (MiRP2) protein levels in the adult mouse VNO.

\section{Coexpression of ERG1, ERG3, and MiRP2 in basal VSNs}

To analyze the spatial distribution of vomeronasal ERG and MiRP2 channel subunits, we performed immunocytochemistry in coronal VNO sections from both $\mathrm{C} 57 \mathrm{BL} / 6$ and transgenic OMP-GFP mice. In the gene-targeted animals, all VSNs express GFP under the control of the omp promoter (Potter et al., 2001). Double-labeling experiments using antibodies against ERG1-3 or MiRP2 together with layer-specific markers of apical neurons [phosphodiesterase 4a (PDE4a) (Lau and Cherry, 2000)] or basal VSNs [V2R2 (Martini et al., 2001)] (supplemental Fig. 2a, available at www.jneurosci.org as supplemental material) revealed coexpression of ERG1, ERG3, and MiRP2 in basal neurons (Fig. $2 a, b$; supplemental Fig. $2 c$, available at www.jneurosci.org as supplemental material). To control for nonspecific staining, we performed immunocytochemical experiments in which primary antibodies were preadsorbed with their corresponding antigenic peptides (supplemental Fig. $2 d$,e, available at www.jneurosci.org as supplemental material). In addition, we routinely performed parallel experiments in which primary antibodies were omitted (supplemental Fig. $3 d$, available at www.jneurosci.org as supplemental material).

In sections from OMP-GFP mice, merged images of antiERG1 and anti-V2R2 labeling show overlapping staining in both the somata and dendritic tips of basal VSNs (Fig. $2 a$ ). In contrast, a spatially restricted pattern was observed by anti-ERG1/antiPDE4a double labeling (supplemental Fig. $2 b$, available at www. jneurosci.org as supplemental material). PDE4a staining was confined to apical cells, whereas essentially nonoverlapping ERG1 labeling was detected in basal neurons. The same results were obtained using another ERG1 antibody (Santa Cruz Bio- 
a
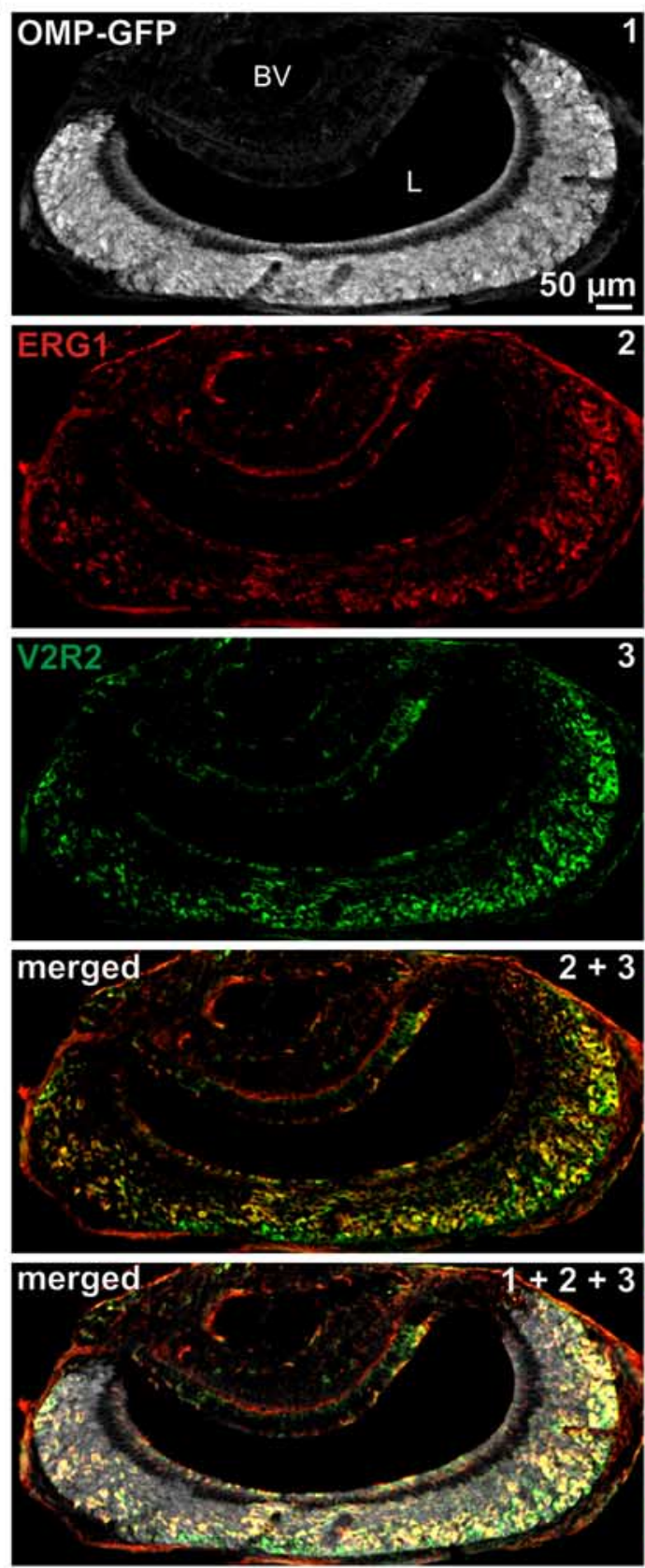

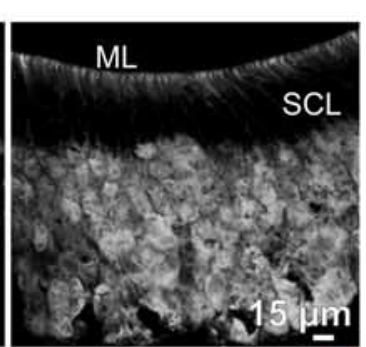

b
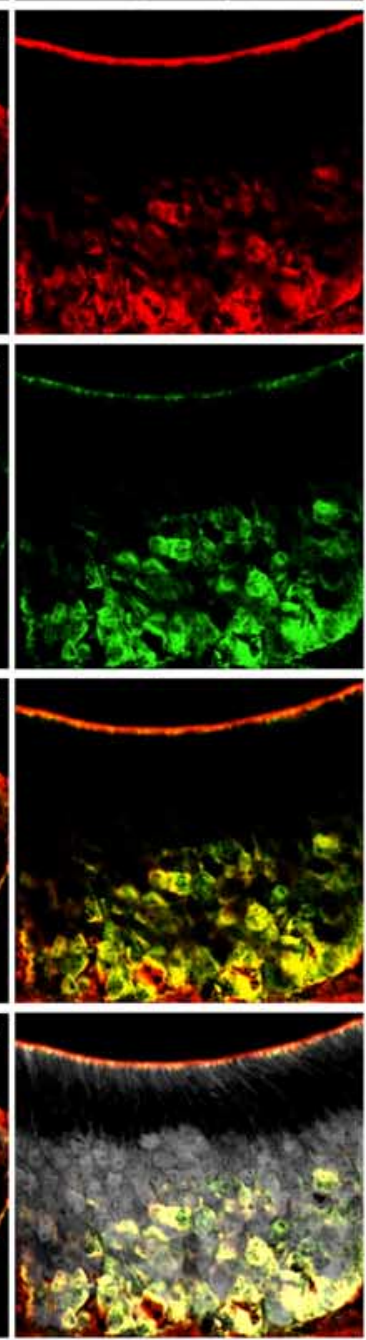
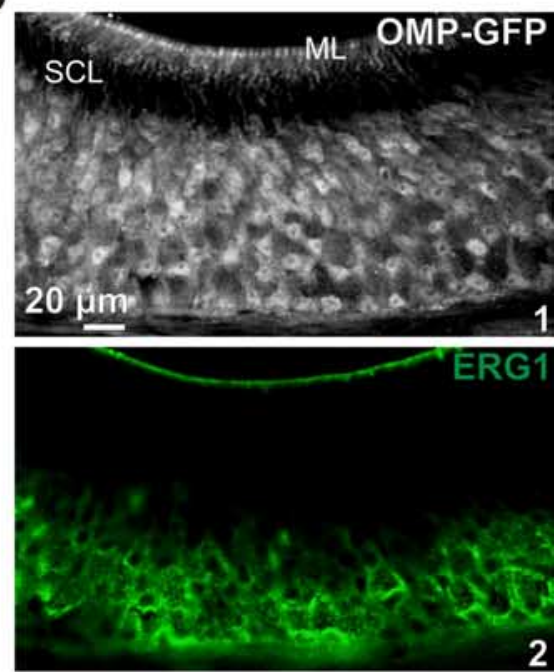

ERG3
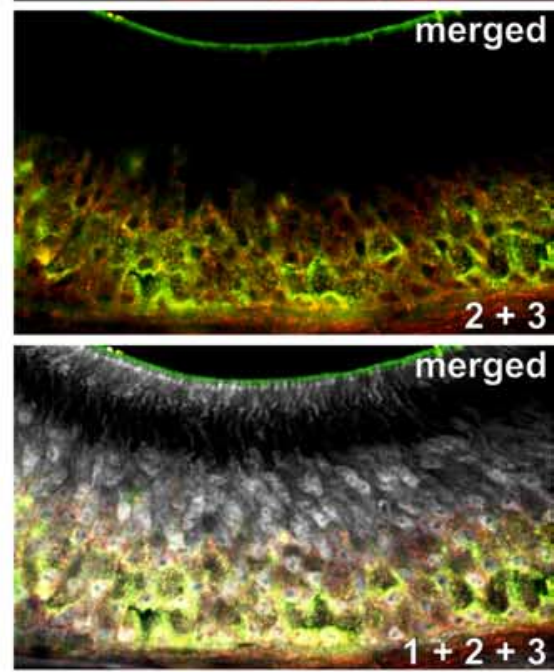

C
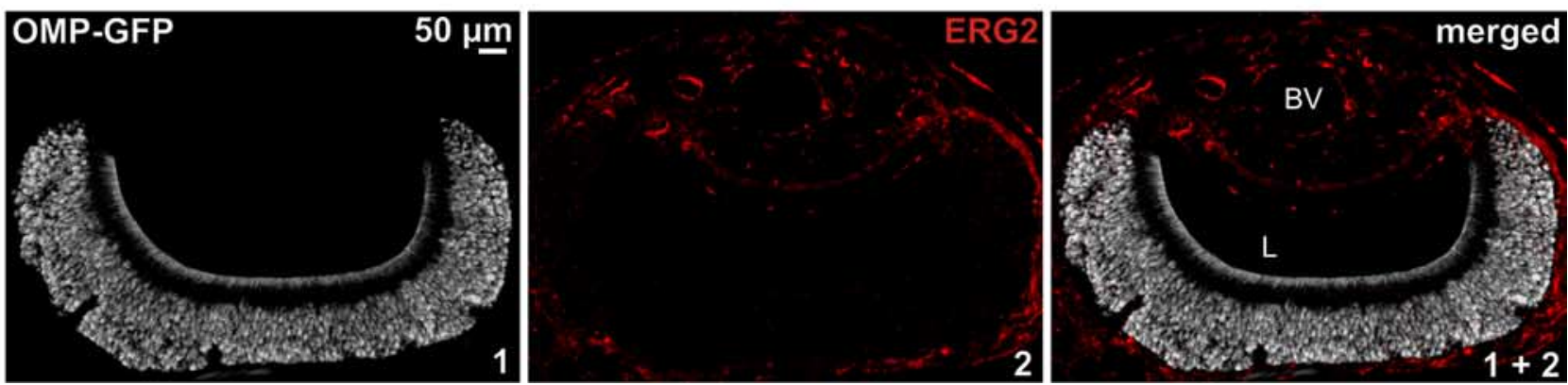

Figure 2. Coexpression of ERG1 and ERG3 in basal VSNs. a, Confocal images of immunostainings in VNO cryosections from OMP-GFP mice (GFP fluorescence; gray scale; 1 ) show costaining of ERG1 (red; 2) and V2R2 (green; 3). High-magnification images (right) reveal overlapping staining in the VSN somata and dendritic tips. $\boldsymbol{b}$, Representative high-magnification confocal images of the VN0 sensory epithelium in a coronal section $(25 \mu \mathrm{m})$ from an OMP-GFP mouse. GFP fluorescence in mature VSNs is depicted in gray scale (1), ERG1-immunopositive cells are shown in green (2), and ERG3-positive VSNs are shown in red (3). Merged images clearly reveal coexpression of ERG1 and ERG3 in basal VSN somata. In contrast to ERG1 immunoreactivity, ERG3 staining is not observed in the microvillous layer. c, Confocal images of ERG2 immunostainings in VNO sections from OMP-GFP mice (GFP fluorescence, gray scale, 1; anti-ERG2 signal is shown in red, 2). Merged photomicrographs reveal essentially no ERG2-positive VSNs. BV, Blood vessel; L, lumen; ML, microvillous layer; SCL, sustentacular cell layer. 
technology; data not shown). Costainings of ERG1 and MiRP2 (supplemental Fig. $2 c$, available at www.jneurosci.org as supplemental material) as well as ERG1 and ERG3 (Fig. 2b) indicate coexpression of all three subunits. Immunostainings against ERG2, however, showed no VSN-specific labeling (Fig. 2c). As positive controls, we immunostained sagittal sections of the cerebellum in which expression of all ERG subunits had previously been reported (Papa et al., 2003; Guasti et al., 2005). Immunoreactivity for ERG1, ERG2, and ERG3 was detected in Purkinje neurons (supplemental Fig. $3 a-c$, available at www.jneurosci.org as supplemental material). Consistent with semiquantitative immunoblotting results (Fig. 1d), when parallel ERG1 immunostainings were performed on VNO cryosections from stimulated $(n=3)$ and deprived $(n=3)$ mice under the exact same conditions, an increase in both fluorescence intensity and the amount of labeled neurons became apparent (supplemental Fig. $3 e$, available at www.jneurosci.org as supplemental material).

The subcellular distribution of ERG1 and MiRP2 was assessed in dissociated VSNs from OMP-GFP mice (supplemental Fig. $4 a, b$, available at www.jneurosci.org as supplemental material). In immunopositive neurons $(n=5)$, ERG1 reactivity was evident in the entire cell body. In contrast, MiRP2 staining was most prominent in the soma and dendrite $(n=4)$ but absent in the knob and microvilli. This pattern confirmed results obtained in whole-organ sections (supplemental Fig. $2 c$, available at www. jneurosci.org as supplemental material). Together, these data show that both ERG1 isoforms (1a and 1b) as well as ERG3 and MiRP2 are coexpressed in basal neurons of the mouse VNO.

\section{Biophysical "fingerprint" of vomeronasal ERG channels: current activation}

We next asked whether ERG channel expression is reflected by voltage-dependent $\mathrm{K}^{+}$currents $\left(I_{\mathrm{K}(\mathrm{ERG})}\right)$. Therefore, we obtained whole-cell recordings from optically identified neurons in acute VNO slices (Kelliher et al., 2006). After break-in, physiological saline was replaced by $\mathrm{S}_{3}$. Exchange was monitored by the gradual block of voltage-gated $\mathrm{Na}^{+}$inward currents in response to step depolarizations [supplemental Fig. $4 c$, available at www. jneurosci.org as supplemental material; note the increase in tail current amplitude (arrowhead)]. In all recordings, step protocols were applied before and after incubation with highly specific ERG inhibitors: either the methanesulfonanilide E-4031 (10 $\mu \mathrm{M})$ (Spector et al., 1996) or the scorpion toxin ErgTx-1 (100 nM) (Gurrola et al., 1999). Digital subtraction of currents recorded in the presence of either drug from control recordings revealed the ERG-mediated component.

To investigate the voltage dependence of quasi steady-state activation, a $750 \mathrm{~ms}$ prepulse to variable potentials ( -70 to 60 $\mathrm{mV}$ ) was followed by a step to $-120 \mathrm{mV}$ (100 ms). After hyperpolarization, rapid recovery from inactivation and slower deactivation induced an E-4031-sensitive tail current in 16 of 27 VSNs (59\%) (Fig. 3a). During depolarization, we observed a substantial E-4031-sensitive steady-state outward current, likely attributable to activation of ERG3. This subunit shows fast activation kinetics and slow steady-state inactivation (Shi et al., 1997; McKay and Huizinga, 2006), resulting in weak inward rectification (Wimmers et al., 2002). Eleven of 27 neurons showed no drug-sensitive current (Fig. 3b). To ensure that diminished tail currents did not result from current rundown, we performed controls in the absence of inhibitors (supplemental Fig. 4d, available at www. jneurosci.org as supplemental material). Up to $10 \mathrm{~min}$, essentially no rundown was observed.

When peak tail current density is plotted as a function of prepulse depolarization (Fig. 3c), a similar voltage dependence is seen for E-4031-sensitive VSNs ( $n=16$ of 27) and ErgTx-1sensitive neurons ( $n=14$ of 18 ). Normalization of tail currents (Fig. $3 d$ ) provides a reasonable estimate for the activated channel fraction (open or inactivated state) before repolarization. Using the Boltzmann equation to fit the activation curves, we obtained half-maximal activation values $\left(V_{1 / 2}\right)$ of $-13.8 \mathrm{mV}(\mathrm{E}-4031)$ and $-7.1 \mathrm{mV}($ ErgTx-1) and slope factors $k=17(\mathrm{E}-4031)$ and $k=16$ (ErgTx-1), respectively. These data show that, although channels begin to activate at subthreshold potentials, a considerable membrane depolarization is required to evoke substantial channel activation.

In addition to voltage-dependent gating characteristics, ion channel function is determined by gating kinetics. To investigate ERG channel activation kinetics in VSNs, we applied an envelope of tail current protocol (Schonherr et al., 1999; Sturm et al., 2005). Depolarizing prepulses $(40 \mathrm{mV})$ of increasing duration (5-2310 ms; increment factor, 1.55) were followed by hyperpolarization to $-120 \mathrm{mV}$ (Fig. 3e). When current densities were plotted as a function of prepulse duration (Fig. $3 f, g$ ), $I_{\mathrm{K}(\mathrm{ERG})}$ amplitude increased exponentially with a time constant $\tau_{\text {act }}=194$ $\mathrm{ms}(n=13)$. Similar values were reported for recombinant $\mathrm{rERG}$ channels $\left[\tau_{\text {act }}=95 \mathrm{~ms}\right.$ (rERG3) to $215 / 123 \mathrm{~ms}$ (rERG1a/ rERG1b)] (Hirdes et al., 2005). However, we observed a significant current $(-37.3 \pm 11.2 \mathrm{pA} / \mathrm{pF})$ even at $5 \mathrm{~ms}$ depolarizations (Fig. $3 f$ ), corresponding to $34.4 \pm 5.3 \%$ of open channels [current normalization $\left(I / I_{\max }\right)$ on a semilogarithmic scale] (Fig. $3 g$ ). Half-maximal activation was observed after $25.8 \mathrm{~ms}$. These results indicate that, provided a substantial membrane depolarization, a considerable fraction of vomeronasal ERG channels displays a relatively rapid time course of activation.

\section{Biophysical fingerprint of ERG channels: current availability and deactivation}

The combination of fast recovery from inactivation and relatively slow deactivation is a characteristic feature of ERG channels (Schwarz and Bauer, 2004) underlying their role in membrane repolarization and modulation of excitability. Therefore, we next studied vomeronasal ERG current availability after repolarization. VSNs were depolarized ( $40 \mathrm{mV}$ ) for $500 \mathrm{~ms}$ to fully activate/ inactivate ERG channels. After repolarization to variable potentials $(-10$ to $-120 \mathrm{mV}, 100 \mathrm{~ms}$ ), drug-sensitive tail current amplitudes and deactivation kinetics are clearly voltage dependent (Fig. 4a). Forty-nine percent (25 of 51; E-4031) and 53\% (8 of 15; ErgTx-1) of all neurons, respectively, exhibited ERGmediated currents (Fig. 4a), whereas no currents were detected in the remaining 26 (E-4031) and 7 (ErgTx-1) VSNs (Fig. 4b). $I_{\mathrm{K} \text { (ERG) }}$ quasi steady-state inactivation curves were derived from peak current densities and fitted by the Boltzmann equation. No significant amplitude differences (one exception at $-30 \mathrm{mV}$ ), similar $V_{1 / 2}$ values for half-maximal recovery from inactivation (E-4031, -62.3 mV; ErgTx-1, -63.8 mV), and slope factors $(\mathrm{E}-4031, k=19 ; \mathrm{ErgTx}-1, k=17)$ illustrate the effective isolation of vomeronasal ERG currents using either blocker (Fig. $4 c, d$ ). Using $S_{3}$, the calculated Nernst equilibrium potential for $\mathrm{K}^{+}$is $-32.5 \mathrm{mV}$. Individual normalized $I_{\mathrm{K}(\mathrm{ERG})}$ availability curves reversed, on average, at $-30.5 \pm 1.5 \mathrm{mV}(\operatorname{ErgTx}-1 ; n=6)$ and $-26.7 \pm 1.3 \mathrm{mV}(\mathrm{E}-4031 ; n=10 ; p=0.078)$, respectively, confirming the $\mathrm{K}^{+}$selectivity. Notably, at potentials of $-60 \mathrm{mV}$ or less, $I_{\mathrm{K}(\mathrm{ERG})}$ deactivation was not complete after $100 \mathrm{~ms}$ (Fig. 4a, expanded traces). When plotting average amplitudes, at $95 \pm 5$ ms after repolarization, versus membrane potential (Fig. 4e), this 
a
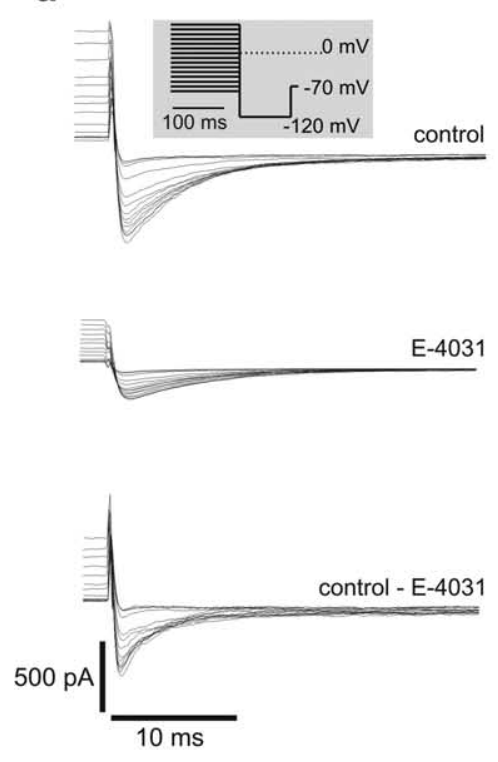

b

control - E-4031

e
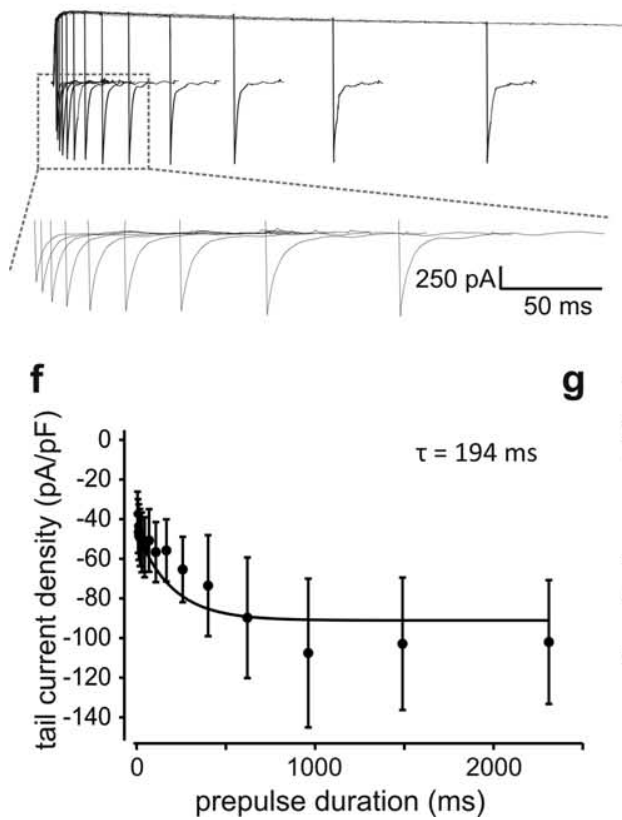

C

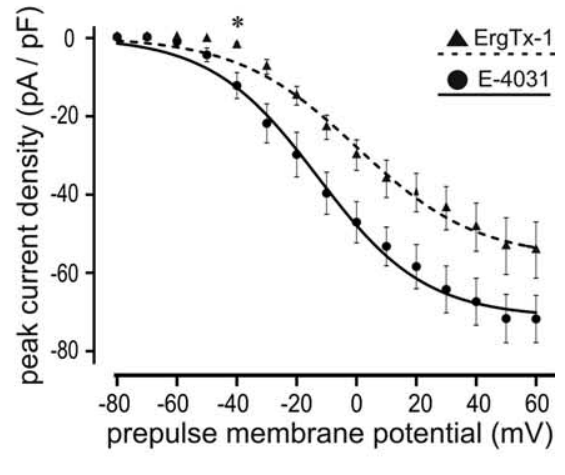

c

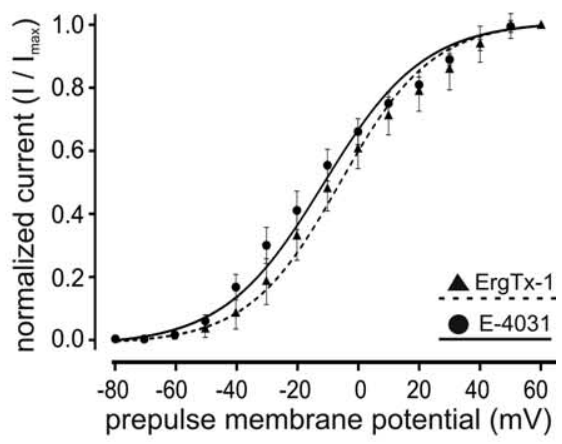

"steady-state" current becomes apparent (E-4031, $n=13$; $\operatorname{ErgTx}-1, n=8)$.

On expanded coordinates (Fig. 4a), the voltage dependence of deactivation becomes evident. Tail current decay was fitted by a single exponential function (gray dashed line) to determine deactivation time constants $\left(\tau_{\text {deact }}\right)$. Currents elicited by strong hyperpolarization (Fig. $4 a,-120$ $\mathrm{mV}$ trace) deactivated faster than currents evoked by step repolarization to less negative potentials (Fig. $4 a,-90 \mathrm{mV}$ trace). This characteristic of ERG channels was quantified by plotting $\tau_{\text {deact }}$ versus the repolarization potential (Fig. $4 f, g$ ). On a semilogarithmic scale, the voltage dependence of $\tau_{\text {deact }}$ was linear (Fig. $4 f$ ). Normalization to values recorded at $-60 \mathrm{mV}$ (E-4031: $21.5 \pm 2.6 \mathrm{~ms}, n=16$; ErgTx-1: $20.3 \pm 5 \mathrm{~ms}, n=5$ ) reveals no inhibitorrelated differences (Fig. 4g). Together, substantial ERG-mediated $\mathrm{K}^{+}$current, consisting of both a deactivating tail and a steady-state current component, is available in basal VSNs during fast repolarization to subthreshold membrane potentials.

\section{The ERG1 channel subunit is a major} contributor to vomeronasal $I_{\mathrm{K}(\mathrm{ERG})}$ $\mathrm{K}^{+}$channel profiling and semiquantitative immunochemistry revealed activitydependent upregulation of ERG1 expression (Fig. 1). Therefore, we aimed to dissect the role of this specific subunit in generation of vomeronasal ERG currents using a pharmacological approach. In contrast to the less selective agents E-4031 and ErgTx-1, the recombinant peptide rBeKm-1 completely blocks ERG1 at nanomolar concentrations without affecting other channels including ERG3 (Korolkova et al., 2001; Restano-Cassulini et al., 2006). We, thus, repeated various experiments shown in Figures 3 and 4 using $\mathrm{rBeKm}-1$ (100 nM) to study activation, recovery from inactivation, and deactivation of isolated ERG1-mediated currents (Fig. 5). Eight of 15 VSNs (53\%) showed rBeKm-1-sensitive currents. Quasi steadystate activation was compared with data obtained when blocking all subunits using E-4031 (Fig. 5a). We found significantly smaller rBeKm-1-sensitive current amplitudes at positive potentials. Activation curves showed similar $V_{1 / 2}$ values for currents isolated by $\mathrm{rBeKm}-1(-18.6 \mathrm{mV})$ and E-4031 $(-13.8 \mathrm{mV})$. However, the slope of the rBeKm-1 curve $(k=23.8)$ was considerably more shallow than for currents isolated by E-4031 $(k=17)$. In experiments addressing current availability after repolarization (Fig. 5b), significantly 
decreased amplitudes are observed in rBeKm-1-treated VSNs after repolarization to membrane potentials of $-80 \mathrm{mV}$ or less. Moreover, half-maximal recovery from inactivation and slope factors were different (E-4031: $-60.3 \mathrm{mV}, k=19$; rBeKm-1: $-71.5 \mathrm{mV}, k=25)$. Notably, no differences in the nondeactivation current component were found using either treatment (Fig. 5c), suggesting that the steady-state current is predominantly, if not exclusively, mediated by homomeric or heteromeric ERG1 channels. In summary, these data indicate that the ERG1 subunit(s) contributes substantially to the total ERG-mediated current. However, a small but significant fraction is carried by $\mathrm{rBeKm}-1$ insensitive subunits.

\section{$I_{\mathrm{K}(\mathrm{ERG})}$ is selectively expressed in basal VSNs}

Immunochemistry revealed that ERG subunits are exclusively found in basal neurons (Fig. 2; supplemental Figs. 2b-e, 3e, available at www.jneurosci.org as supplemental material). If so, ERG-mediated currents should only be expressed in $\sim 50 \%$ of all VSNs. Indeed, we observed $I_{\mathrm{K}(\mathrm{ERG})}$ in $53 \%$ (41 of 78; E-4031), 67\% (22 of 33 ; ErgTx-1), and $53 \%$ (8 of 15 ; rBeKm-1) of investigated neurons. To consolidate these findings, we labeled several VSNs $(n=11)$ during voltage-clamp analysis by adding Alexa488 hydrazide (20 $\mu \mathrm{M})$ to the pipette solution. This allowed on-line in situ visualization of VSN morphology (Fig. 6a, left and middle), post hoc immunocytochemical analysis (Fig. 6b-f), and 3-D reconstruction (Fig. $6 a$, right $(n=$ 7) (supplemental Movie 1, available at www.jneurosci.org as supplemental material). All labeled neurons exhibited an intact cytoarchitecture. Given the rather diffuse zonal boundary in the VNO (Fig. 2; supplemental Fig. 2, available at www. jneurosci.org as supplemental material) (Martini et al., 2001; Leinders-Zufall et al., 2004), it was, however, impossible to infer basal or apical identity of a given neuron simply from in situ visualization. We therefore determined cell identity by post hoc immunocytochemistry using antiV2R2 (Fig. 6b,d), anti-PDE4a (Fig. 6c,e), and anti-ERG1 (Fig. $6 f$ ) antibodies. All labeled VSNs that showed ERG-mediated currents $(n=8)$ were immunopositive for either ERG1 $(n=4)$ or V2R2 $(n=2)$ or showed no PDE4a staining $(n=2)$, respectively (Fig. 6b,c). In contrast, cells that exhibited no current $(n=3)$ were either negative for V2R2 (Fig. 6d) or ERG1 (Fig. $6 f$ ) or strongly stained by the anti-PDE4a
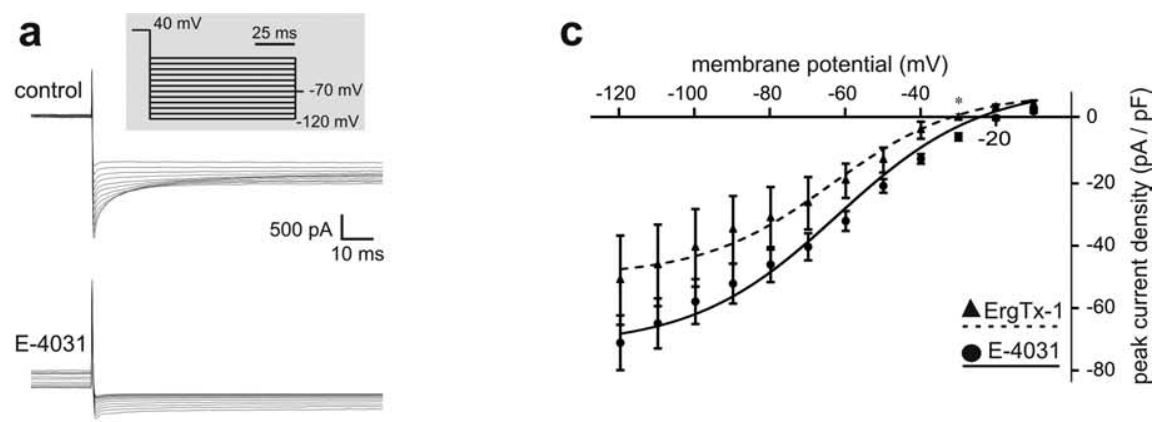

d
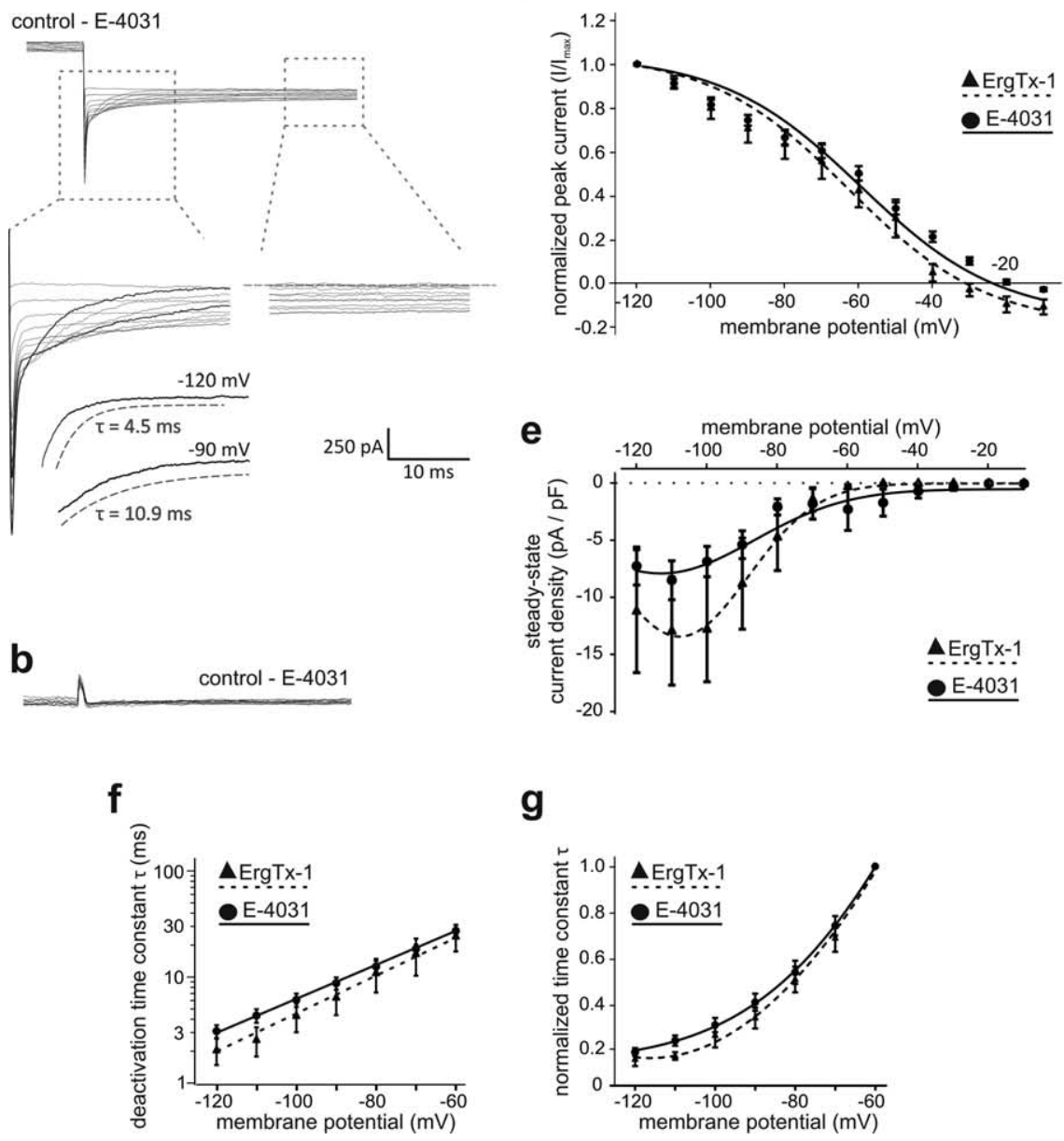

Figure 4. Voltage dependence of ERG channel deactivation. $\boldsymbol{a}-\boldsymbol{d}$, ERG current availability depends on the degree of repolarization. $\boldsymbol{a}$, Representative original tail currents recorded during repolarization steps to variable membrane potentials $(-10$ to $-120 \mathrm{mV}$; inset, pulse protocol). Recordings are shown under control conditions, in the presence of E-4031 (10 $\mu \mathrm{m})$ and after digital off-line subtraction (control - E-4031). On expanded coordinates (dotted square area; left), the voltage dependence of current availability becomes obvious $(n=25)$. $\boldsymbol{b}$, In 26 VSNs, essentially no drug-sensitive currents could be isolated. c, $\boldsymbol{d}$, Quasi steady-state $I_{K(E R G)}$ inactivation curves derived from peak current densities $(\boldsymbol{c})$ or normalized current amplitudes $\left(\boldsymbol{d} ; I / I_{\max }\right)$ and plotted as a function of the repolarization voltage [filled circles, E-4031, $n=25$; filled triangles, ErgTx-1 (100 nм), $n=8$ ]. Data points are fitted by the Boltzmann equation. With one exception $(\boldsymbol{c} ;-30 \mathrm{mV})$, no significant differences are observed between curves derived using either inhibitor. $\boldsymbol{e}$, Steady-state current density after $95 \mathrm{~ms}$ of repolarization (E-4031, $n=13$; ErgTx-1, $n=$ 8). At membrane potentials of $-60 \mathrm{mV}$ or less, a nondeactivating or slowly deactivating current is recorded ( $\boldsymbol{a}$; expanded dotted square area; right). Trend lines were extrapolated using a Gauss function. $\boldsymbol{f}, \boldsymbol{g}$, Voltage dependence of deactivation kinetics (filled circles, E-4031, $n=16$; filled triangles, ErgTx-1, $n=5$ ). $\tau_{\text {deact }}$ was determined by single-exponential fits during a fixed time period (2-25 ms after repolarization). On a semilogarithmic scale $(\boldsymbol{f}), \tau_{\text {deact }}$ versus repolarization potential shows a linear relationship. When $\tau_{\text {deact }}$ values are normalized to data obtained at $-60 \mathrm{mV}(\boldsymbol{g})$, no differences in deactivation kinetics are observed using either ERG inhibitor. 
a

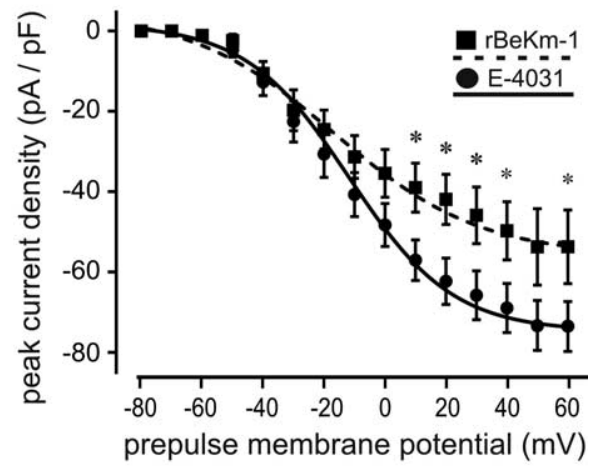

b

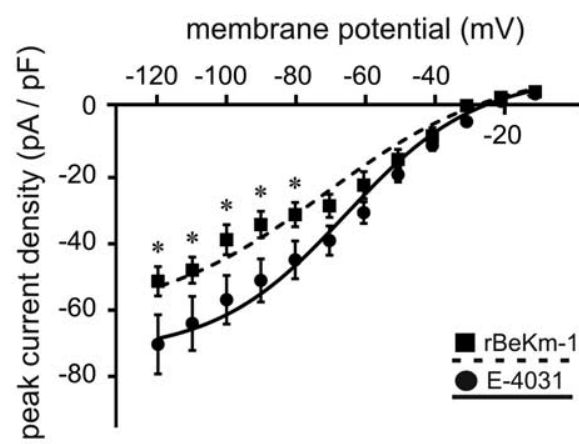

C

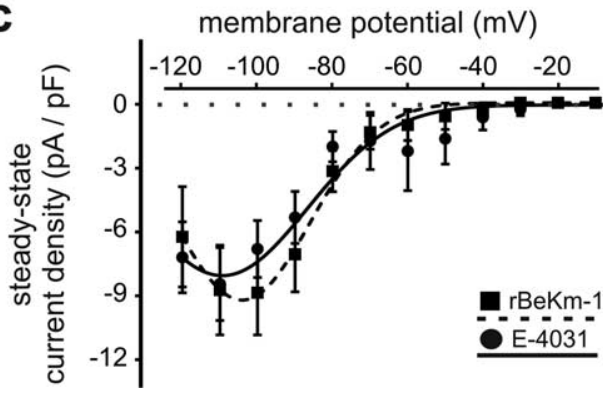

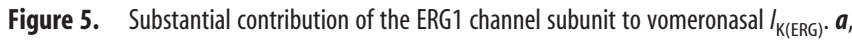
Quasi steady-state activation of vomeronasal ERG currents (see Fig. 3c) [filled circles, E-4031 (10 $\mu \mathrm{M}), n=16$; filled squares, rBeKm-1 (100 nM), $n=8$ ]. Current densities are shown as a function of prepulse potential and fitted by the Boltzmann equation. At depolarization to positive voltages (10-40 mV and $60 \mathrm{mV})$, rBeKm-1-sensitive amplitudes are significantly smaller than currents isolated using the nonsubunit-selective agent E-4031 ( $p<0.05)$. $\boldsymbol{b}$, Significant differences in channel availability after repolarization (filled squares, rBeKm-1, $n=8$; filled circles, $\mathrm{E}-4031, n=25$ ). Inactivation curves show significantly decreased peak densities for ERG1-specific currents at potentials of $-80 \mathrm{mV}$ or less $(p<0.05)$. c, Similar steady-state current characteristics are detected using either pharmacological treatment. Trend lines are calculated using a Gauss function.

(Fig. 6e) antibody. ERG-mediated currents are thus unique to basal V2R-expressing neurons.

\section{Regulated transcription is effectively translated into changed protein functionality}

We next asked whether the reduced ERG1 channel expression in stimulus-deprived mice (Fig. 1) is reflected in VSN electrophysiology. To address this question, we recorded ERG-mediated currents in optically identified basal VSNs (Kelliher et al., 2006) from stimulus-deprived animals $(n=9)$. Using the same pulse protocols as shown in Figures $3 a$ and $4 a$, we recorded both E-4031- and $\mathrm{rBeKm}$-1-sensitive tail currents as a function of either prepulse (Fig. 6g,i) or repolarization (Fig. 6h,j) potential, respectively. In- deed, using either E-4031 to isolate total ERG currents or $\mathrm{rBeKm}-1$ to specifically isolate the ERG1-dependent component, current densities were significantly reduced in VSNs from deprived mice. When data from deprived animals (E-4031) were fitted by the Boltzmann equation, the slopes of both the $I_{\mathrm{K} \text { (ERG) }}$ activation $(k=20)$ and the availability curve $(k=27)$ were considerably shallower than observed for control neurons $(k=17)$ 19) (Fig. $6 g, h$ ), indicating not only a reduced density of functional channels but also a relative change in subunit composition. Notably, when ERG1-specific currents were isolated from VSNs of control versus deprived mice using $\mathrm{rBeKm}-1$, we observed significantly reduced current densities in deprived mice (Fig. 6i,j), indicating that the substantial reduction in total $I_{\mathrm{K}(\mathrm{ERG})}$ in VSNs from stimulus-deprived mice is, at least in part, attributable to decreased ERG1 expression. This conclusion is supported by the fact that we never observed a nondeactivating current in deprived mice. Because rBeKm-1-sensitive steady-state currents were almost indistinguishable from controls (Fig. 5c), this lack of a steady-state current supports the concept of ERG1 being a critical subunit for incomplete deactivation at hyperpolarized voltages.

\section{$I_{\mathrm{K}(\mathrm{ERG})}$ contributes to the late phase of AP repolarization} in VSNs

Several biophysical characteristics of vomeronasal ERG currents suggest a potential function in AP repolarization. First, considerable membrane depolarization (e.g., during AP overshoot) is required to evoke substantial activation (Fig. 3a,d). Second, significant currents are observed even at preceding depolarizations as short as $5 \mathrm{~ms}$ (Fig. 3f). Third, little inactivation occurs during depolarization (Fig. 3e). Do ERG channels thus contribute to spike repolarization in VSNs? To clarify this question, we recorded E-4031-sensitive currents using the AP clamp technique. Prerecorded AP trains elicited by positive current injection into VSNs were applied as the command waveforms (black traces). This way, vomeronasal ERG channels experience the same trajectory of voltage as during naturally occurring APs (Bean, 2007). Figure $7 a$ shows a drug-sensitive current that is rapidly activated and shifted from outward to inward during the repolarizing phase $(n=24)$. On expanded coordinates (Fig. $7 a$, right), this current reversed close to the calculated Nernst $\mathrm{K}^{+}$equilibrium potential of $-32.5 \mathrm{mV}$ (red dotted lines), reached a peak close to the point of maximal repolarization $(-70 \mathrm{mV}$; black dotted lines), and decayed exponentially with a mean time constant of $\tau_{\text {deact }}=17.9 \pm 4.3 \mathrm{~ms}$.

We next asked whether the duration of interspike episodes affects the ERG current amplitude. Frequency-dependent ERG current accumulation has previously been observed (Chiesa et al., 1997; Schonherr et al., 1999). When a train of VSN APs, showing spike frequency adaptation during constant current injection, was used as a stimulus template, ERG amplitudes decreased with prolonged interspike intervals (Fig. 7b) (control/E-4031, $n=14$; control/rBeKm-1, $n=14$; deprived/rBeKm-1, $n=9$ ). At discharge intervals longer than $\sim 150 \mathrm{~ms}$, however, peak current densities remain relatively stable, indicating that at frequencies $\geq 7 \mathrm{~Hz}$ incomplete ERG channel deactivation between spikes could lead to current accumulation. Moreover, AP-driven ERG currents are strongly ERG1 dependent (Fig. $7 b$, right). Total $I_{\mathrm{K}(\mathrm{ERG})}$ amplitudes (E-4031) and the ERG1-specific current component $(\mathrm{rBeKm}-1)$ are not statistically different, although the latter tends to be consistently smaller. In VSNs from deprived animals, however, ERG1-dependent current flow during AP discharge is strongly reduced (red graph). In summary, these data 
a
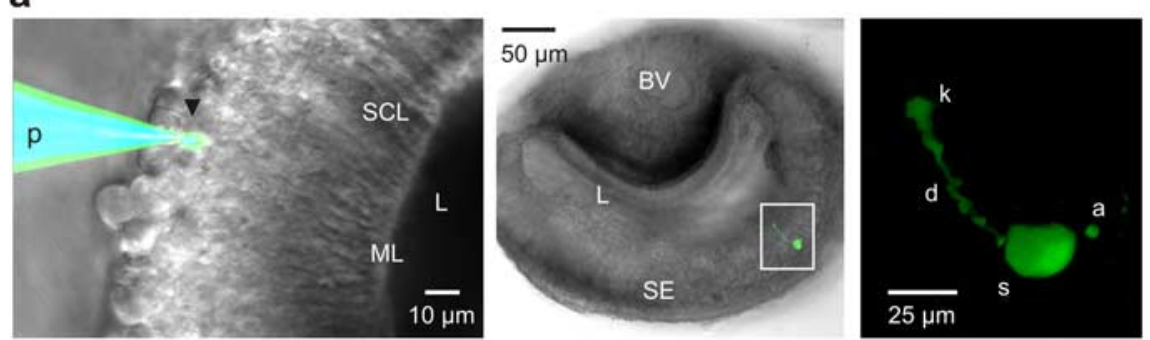

b

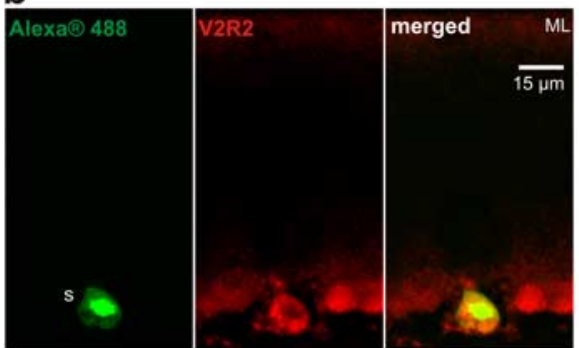

C

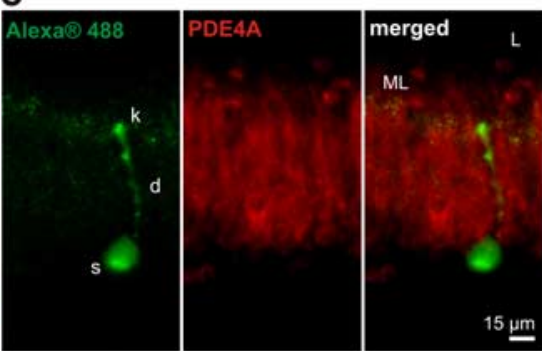

d

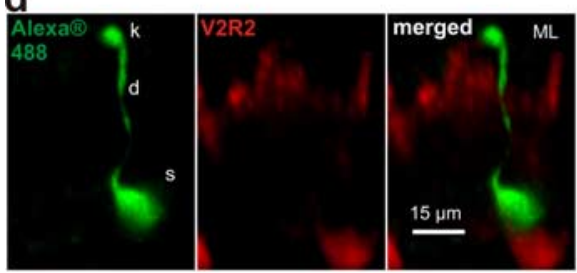

g

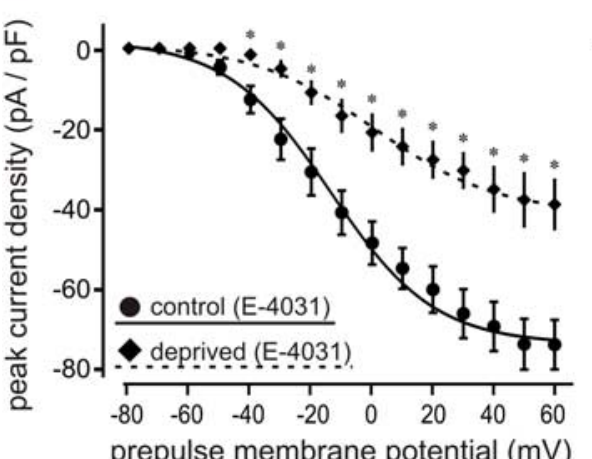

i

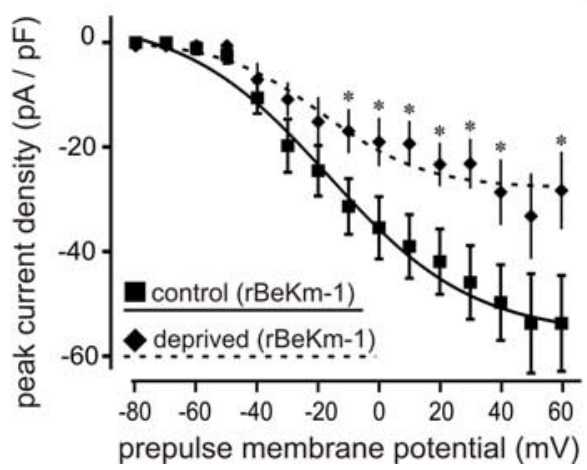

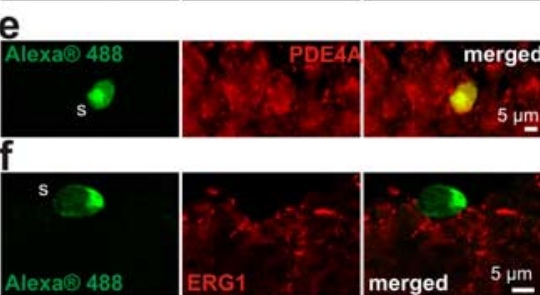

h

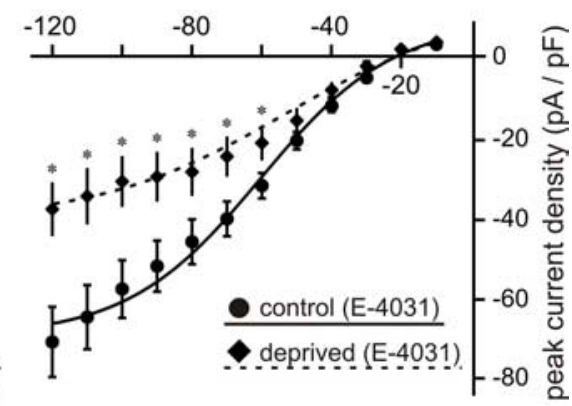

j

membrane potential $(\mathrm{mV})$

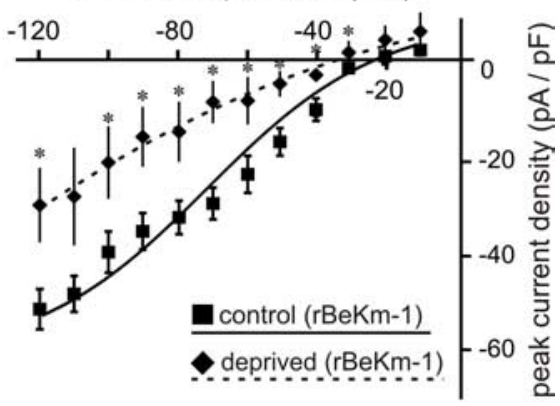

Figure 6. Sensory activity controls ERG $\mathrm{K}^{+}$channel expression and function in basal VSNs. $\boldsymbol{a}$, During whole-cell experiments, cells were fluorescently labeled via diffusion of Alexa488 for in situ visualization, post hoc immunocytochemical analysis, and 3-D reconstruction of VSN morphology. Left, Overlay of two photomicrographs of an acute VNO slice taken under infrared-DIC illumination and epifluorescence, respectively. The soma (black arrowhead) of the VSN under investigation is visualized by dye diffusion from the pipette. Middle, Low-magnification bright-field image of a VNO slice after recording. Under epifluorescence, the recorded neuron is readily identified (inset). Right, 3-D reconstruction of the same fluorescently labeled VSN shown before (middle; inset). An axial transparency projection is generated from confocal z-stacks (supplemental Movie 1, available at www.

show that considerable ERG1-dependent currents flow during the late repolarizing phase of vomeronasal AP discharge.

$I_{\mathrm{K}(\mathrm{ERG})}$ extends the dynamic range of the vomeronasal stimulus-response function

What is the physiological relevance of ERG channel activation during AP firing? We addressed this question by recording VSN input-output relationships in currentclamp configuration (supplemental material, available at www.jneurosci.org) under physiological ionic conditions. The majority of VSNs were spontaneously active at rest. We therefore injected a constant hyperpolarizing current $(-0.5$ to $-3 \mathrm{pA})$ to keep $V_{\mathrm{M}}$ as close as possible to $-75 \mathrm{mV}$, thereby abolishing spontaneous firing. First, we investigated VSN output in response to a naturally occurring receptor current profile. We designed a current injection protocol that mimicked a basal VSN response that we recorded after application of diluted urine (Fig. 8a, gray box, top). This protocol was applied for five cycles of increasing duration (Fig. $8 a$, gray box, bottom, a-e). VSN firing patterns were analyzed in the absence and presence of E-4031 (10 $\mu \mathrm{M})$. Six of 13 VSNs showed a dramatic effect on AP firing. In these neurons, the number of spikes was significantly reduced after drug incubation (Fig. 8b). Notably, this effect was most pronounced during the initial phase of high-amplitude current injection (25 $7 \mathrm{pA}$ ). Here, we frequently observed that VSNs ceased firing after one or a few initial spikes, but returned to a tonic discharge

jneurosci.org as supplemental material). $\boldsymbol{b}-\boldsymbol{f}$, Layer-specific classification of Alexa488-labeled VSNs by post hoc immunocytochemistry. V2R2, PDE4a, or ERG1 counterstaining shows that VSNs that exhibited ERG currents in previous voltageclamp recordings $(n=8)$ are V2R2 positive (b) or PDE4a negative (c), respectively, whereas neurons that showed no ERGdependent currents are either negative for V2R2 (d) or ERG1 $(\boldsymbol{f})$ or PDE4a positive $(\boldsymbol{e}) . \boldsymbol{g}-\boldsymbol{j}$, ERG currents are reduced in VSNs of stimulus-deprived mice. $\boldsymbol{g}, \boldsymbol{i}$, Activation curves of either E-4031-sensitive ( $\boldsymbol{g}$ ) or rBeKm-1-sensitive (i) ERG currents from stimulus-deprived (filled diamonds; $\boldsymbol{g}, n=9 ; \boldsymbol{i}$, $n=11$ ) and control ( $\boldsymbol{g}$, filled circles, $n=16$; $\boldsymbol{i}$, filled squares, $n=8)$ animals. At depolarizations of $-40 \mathrm{mV}$ or more $(\boldsymbol{g})$ or $-10 \mathrm{mV}$ or more $(i)$, respectively, the reduction is highly significant ( $p \leq 0.005) . \boldsymbol{h}, \boldsymbol{j}, I_{\mathrm{K}(\mathrm{ERG})}$ availability curve for stimulus-deprived (filled diamonds; $\boldsymbol{h}, n=8 ; \boldsymbol{j}, n=7$ ) and control ( $\boldsymbol{h}$, filled circles, $n=25 ; \boldsymbol{j}$, filled squares, $n=8$ ) mice. Current densities are significantly smaller after repolarization to voltages of $-60 \mathrm{mV}$ or less $(\boldsymbol{h})$ or $-30 \mathrm{mV}$ or less $(\boldsymbol{j})$, respectively ( $p \leq 0.05$ ). a, Axon; BV, blood vessel; $d$, dendrite; $k$, knob; L, lumen; ML, microvillous layer; $p$, patch pipette; S, soma; SCL, sustentacular cell layer; SE, sensory epithelium. 


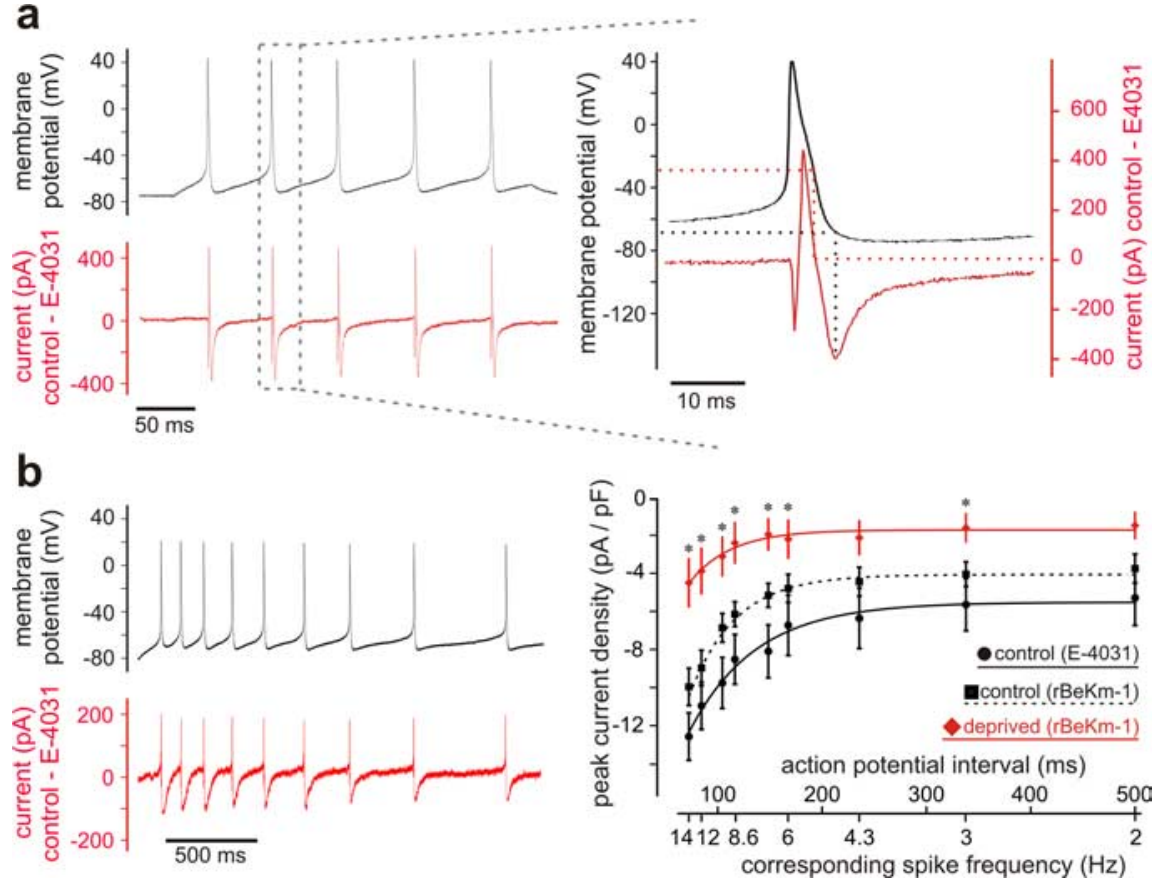

Figure 7. Activation of $I_{\mathrm{K}(\mathrm{ERG})}$ during VSN AP repolarization. $\boldsymbol{a}$, When prerecorded VSN spike trains are applied as the command voltage (AP clamp; black waveforms), E-4031-sensitive currents are observed after digital subtraction (red trace; $n=24)$. A single representative event (dotted square) is shown at higher resolution (right). During AP discharge, an outward current is activated that reverses direction during repolarization, reaches a maximum at $-70 \mathrm{mV}$ (black dotted lines), and decays exponentially. The observed reversal potential is close to the calculated Nernst $\mathrm{K}^{+}$equilibrium potential of $-32.5 \mathrm{mV}$ (red dotted lines). $\boldsymbol{b}$, Representative AP clamp recording (left; red trace) at a command voltage spike train displaying frequency adaptation (black). Quantitative analysis (right) of ERG current amplitudes versus interspike intervals is shown. Total $I_{\text {K(ERG) }}$ is isolated from control VSNs using E-4031 (10 $\mu \mathrm{m} ; n=14$; black circles, solid line), whereas ERG1-dependent currents are isolated by rBeKm-1 [100 nm; black squares, dashed line (control, $n=14$ ); red diamonds, solid line (deprived, $n=9$ )]. Current densities decrease exponentially with prolonged interspike intervals. In VSNs from deprived animals, $I_{\mathrm{K}(\mathrm{ERG})}$ is significantly reduced ( $p \leq 0.05$ ).

jection of suprathreshold current (10 pA; $45 \mathrm{~ms} ; 50$ cycles at $5 \mathrm{~ms}$ intervals). Supplemental Figure $5 a$ (available at www. jneurosci.org as supplemental material) shows representative examples of 50 normalized and averaged spikes of the same neuron in the absence (black trace) or presence (red trace) of E-4031, respectively. Here, spike width is increased from $5.05 \mathrm{~ms}$ (control) to $5.85 \mathrm{~ms}$ (E-4031). Eleven VSNs were examined for both halfwidth (supplemental Fig. $5 c$, available at www.jneurosci.org as supplemental material) and maximal membrane repolarization (supplemental Fig. 5b, available at www.jneurosci.org as supplemental material) during current injection. Because the same cells were also used for experiments shown in Figure 8, $c$ and $d$, we were able to categorize these VSNs as either drug sensitive ( $n=7$; red data points) or insensitive ( $n=4$; black data points). E-4031sensitive neurons show a significant shift of the maximally repolarized membrane potential toward more depolarized values (control, $-67.1 \pm 1.4 \mathrm{mV}$; E-4031, $-58.8 \pm 1.3 \mathrm{mV} ; p=0.008)$ and a significant increase in half-width (control, $4.8 \pm$ $0.18 \mathrm{~ms} ; \mathrm{E}-4031,5.66 \pm 0.44 \mathrm{~ms} ; p<$ $0.005)$ ). A similar broadening of spike width during ERG channel inhibition has been shown for immature Purkinje neurons (from 5.1 to $6.3 \mathrm{~ms}$ ) (Sacco et al., 2003). Again, when comparing single VSN spikes from stimulated ( $n=13)$ versus de-

pattern during small-amplitude current injection (7 - $2 \mathrm{pA})$ (Fig. $8 a$, traces $\mathrm{d}$ and e). Analog results were obtained from analysis of firing patterns in deprived mice (Fig. $8 a, b$, red) $(n=36)$. These data suggest that, by ensuring a sufficient level of membrane repolarization, vomeronasal ERG currents could play a critical role during periods of strong sensory activation.

If the above hypothesis is true, the effect should become more pronounced with increased spike frequencies. Indeed, when the firing rate is analyzed as a function of current injection amplitude (4-40 pA; $1 \mathrm{~s}$ duration), the mean spike frequencies are significantly reduced in the presence of E-4031 at amplitudes $\geq 8 \mathrm{pA}$ (Fig. $8 c, d)(n=11$ of $15 \mathrm{VSNs})$. This effect of pharmacological ERG channel inhibition mimics the impaired AP firing phenotype observed in VSNs from stimulus-deprived animals (Fig. $8 c, d$, red) $(n=30)$. However, maintenance of a constant resting potential (supplemental Fig. $4 e$, available at www.jneurosci.org as supplemental material) $(n=12)$ and spontaneous activity (supplemental Fig. $4 f$, available at www.jneurosci.org as supplemental material) $(n=3)$ were essentially unaffected by ERG channel inhibition. We thus conclude that basal VSNs express $I_{\mathrm{K}(\mathrm{ERG})}$ to guarantee an appropriate input-output relationship at intermediate to high levels of sensory stimulation.

To substantiate this concept, we analyzed changes in the "anatomy" of single spikes both during ERG channel inhibition (supplemental Fig. $5 a-c$, available at www.jneurosci.org as supplemental material) and in stimulated compared with deprived mice (supplemental Fig. $5 d-f$, available at www.jneurosci.org as supplemental material). Single APs were elicited by repeated in- prived ( $n=21)$ mice, the deprivation phenotype (supplemental Fig. $5 d-f$, available at www.jneurosci.org as supplemental material) matches the effects of pharmacological treatment observed in control VSNs. Together, these data strongly suggest that vomeronasal ERG channels are important determinants of AP shape and VSN set-point excitability.

\section{Discussion}

Despite the critical role of the accessory olfactory system in regulation of social and reproductive behaviors, many physiological mechanisms underlying sensory signaling in VSNs remain unclear. Here, we show that basal vomeronasal neurons display a previously unrecognized form of homeostatic plasticity by regulating $\mathrm{ERG} \mathrm{K}^{+}$channel expression in an activity-dependent manner. These channels emerge as important determinants of VSN excitability and thus of sensory gain control in the accessory olfactory system.

Neuronal ERG channel physiology is poorly understood (Sanguinetti and Tristani-Firouzi, 2006) and, so far, functional ERG channels have not been described in peripheral sensory neurons. Our results show that both ERG1 isoforms, ERG3 and the auxiliary $\beta$-subunit MiRP2, are coexpressed in basal VSNs. ERG3 and MiRP2 expression were primarily confined to VSN somata, whereas ERG1 staining was also found in the dendritic tips. Overlapping expression suggests that currents could be determined, at least in part, by heteromeric ERG channels (Wimmers et al., 2001), potentially forming complexes with pluripotent modulatory MiRP2 $\beta$-subunits (McCrossan et al., 2003). As shown by 
a
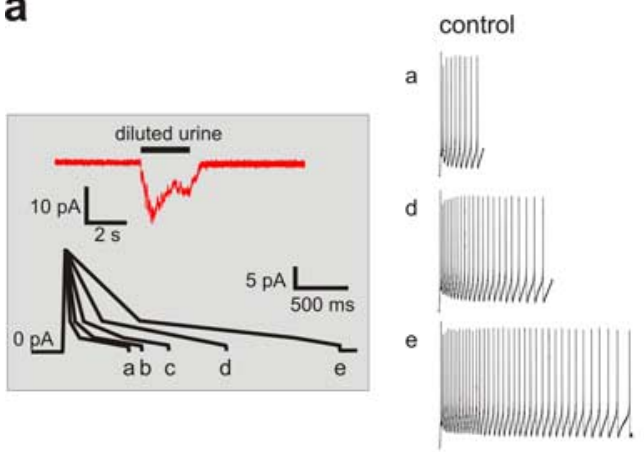

b

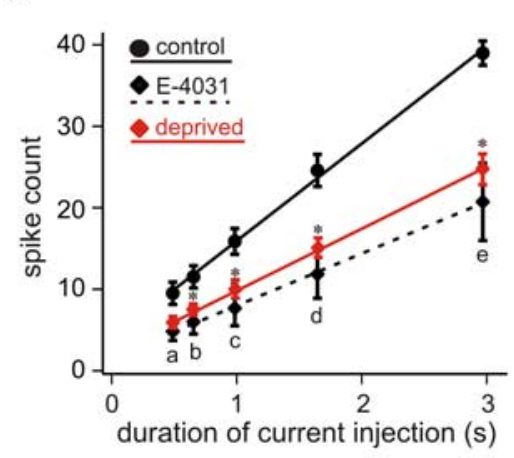

C

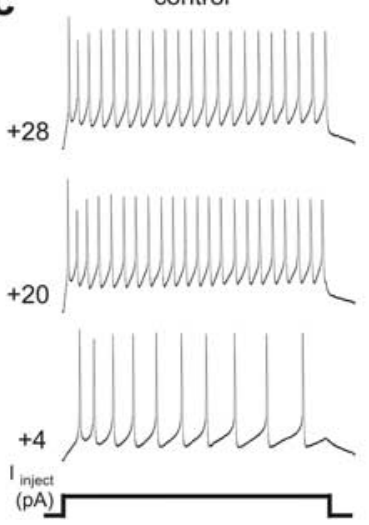

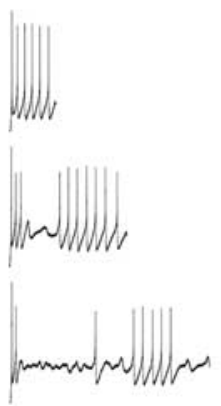

deprived

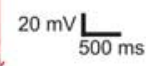

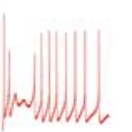
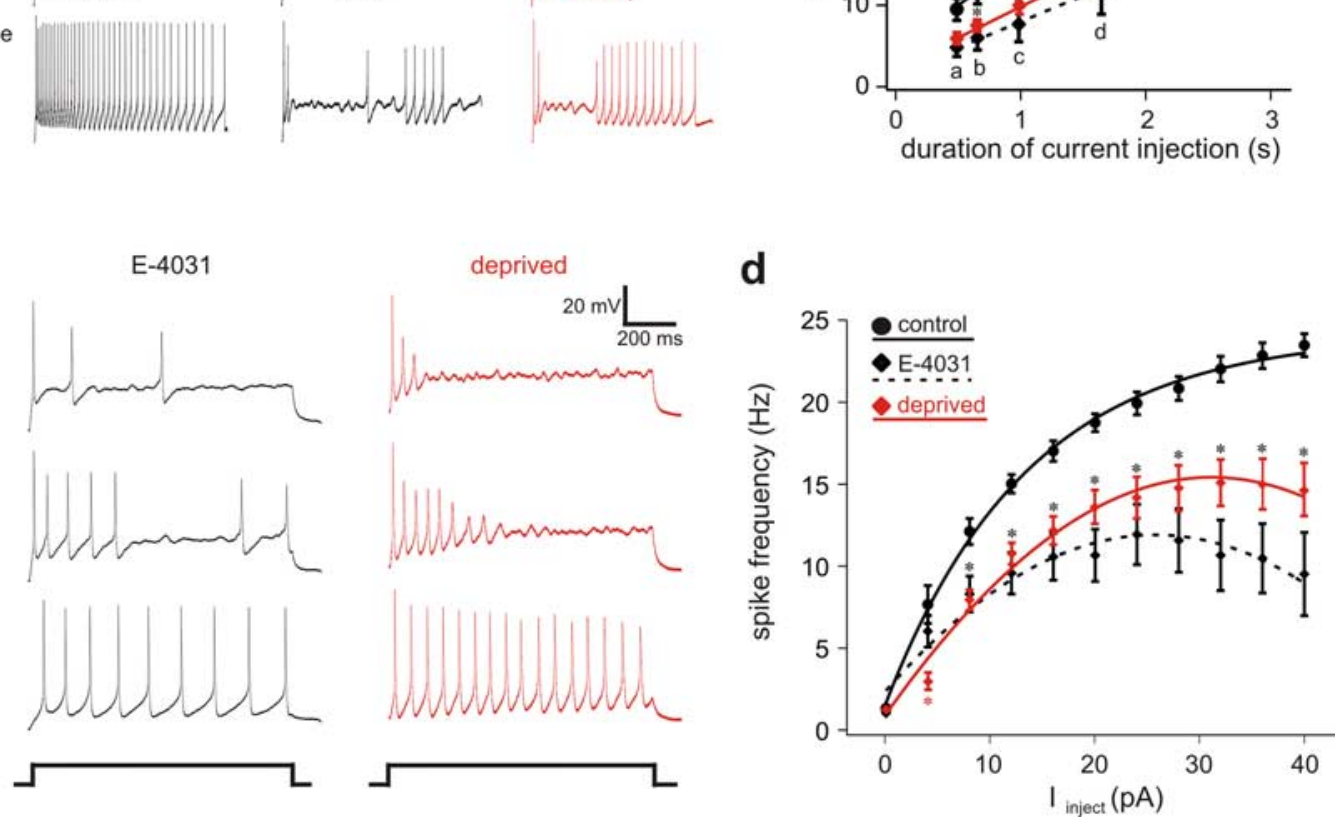

Figure 8. ERG channels determine the output range of basal vomeronasal neurons. $\boldsymbol{a}$, Representative AP discharge patterns induced by current injections. The injection protocol (gray box) mimics a prerecorded VSN receptor current profile in response to focal application of diluted urine (1:100; red trace). High-frequency firing is impaired in response to current injections both after ERG channel inhibition and VSNs of stimulus-deprived animals. Lowercase letters indicate corresponding injection protocols. $\boldsymbol{b}$, Mean number of spikes versus current injection length ( $\boldsymbol{a}$ ) in control VSNs ( $n=$ 6; black circles, solid line), after ERG channel inhibition ( $n=6$; black diamonds, dashed line), and in VSNs from deprived animals ( $n=36$; red diamonds, solid line). Drug incubation and deprivation significantly reduce the total spike count at durations $\geq 500 \mathrm{~ms}(p \leq 0.05)$. $c$, Typical firing responses induced by constant $1 \mathrm{~s}$ depolarizing current steps of variable amplitude ( $4-40 \mathrm{pA} ; 4 \mathrm{pA}$ increments). Note the continuous decline in AP amplitude (deprivation/ERG channel inhibition) as a putative result from reduced membrane repolarization and, consequentially, insufficient recovery from $\mathrm{Na}^{+}$channel inactivation. $\boldsymbol{d}$, Mean firing frequency versus current amplitude ( $f$ - $/$ curve). For amplitudes $\geq 4 \mathrm{pA}$ (deprived, $n=30$ ) or $\geq 8 \mathrm{pA}$ ( $\mathrm{E}-4031, n=11$ ), respectively, the frequency is significantly reduced $(p<0.005)$. Under control conditions, firing rates approximate a maximum frequency of $\sim 25 \mathrm{~Hz}$. After deprivation or ERG channel inhibition, the $f-I$ curve shows a more bell-shaped appearance.

immunoblotting, both ERG1 isoforms are found in the VNO. The exclusive staining of basal VSNs suggests that both splice variants are coexpressed in a given cell and potentially coassemble in heteromeric complexes (Guasti et al., 2005). However, we can neither rule out selective isoform expression in subgroups of basal VSNs nor exclude segregated homomeric expression in individual neurons.

To address the functional implications of vomeronasal ERG channel expression, targeted gene disruption represents one possible strategy. However, homozygous ERG1-deficient mice die early in development (Nerbonne et al., 2001; Salama and London, 2007). We therefore used a pharmacological approach. Given the severe pathophysiological phenotype of ERG channel gene mutations, the pharmacological profile of ERG channels has been intensely scrutinized (Sanguinetti and Tristani-Firouzi, 2006). In this study, we used E-4031 and the two unrelated peptide toxins ErgTx-1 and rBeKm-1 for pharmacological current dissection. Both E-4031 and ErgTx-1 are highly ERG specific, but not sufficiently subunit selective. In contrast, $\mathrm{rBeKm}-1$, a closed channel blocker, discriminates between ERG1 $\left(\mathrm{IC}_{50}, \sim 3 \mathrm{nM}\right)$ and ERG3 ( IC $_{50}, \sim 1 \mu \mathrm{M}$ ) (Korolkova et al., 2001). All inhibitors effectively isolated ERG-mediated currents from basal VSNs. For
E-4031, ERG selectivity results from high-affinity binding to two inner pore aromatic residues that are substituted in other $\mathrm{K}^{+}$ channels. ErgTx-1 also interacts with the channel pore and, at the concentration used, does not affect other $\mathrm{K}^{+}$channels including members of the closely related EAG family. E-4031 and ErgTx-1 did not display significant differences in inhibition potency, whereas rBeKm-1 (100 nM) isolated substantial, although significantly smaller, currents. These results suggest that a large fraction of vomeronasal ERG current depends on functional ERG1 channels, either as homomers or crucial subunits of heteromeric channels.

In several kinetic aspects, vomeronasal ERG channels differ from heterologously expressed channels. Effective channel activation, even during $5 \mathrm{~ms}$ voltage steps, requires substantial depolarization ( $V_{1 / 2}$ : E-4031, - $13.8 \mathrm{mV}$; ErgTx-1, - $7.1 \mathrm{mV}$ ). Similar values were reported for recombinant ERG1 (Lees-Miller et al., 1997; Hirdes et al., 2004; Sturm et al., 2005), whereas more negative $V_{1 / 2}$ potentials (approximately $-50 \mathrm{mV}$ ) were described for ERG3 (Hirdes et al., 2005; Sturm et al., 2005). Vomeronasal ERG currents deactivated considerably faster than recombinant channels (Wimmers et al., 2002; Sturm et al., 2005). Accelerated deactivation, however, has also been observed for other endogenous 
mouse ERG currents (McKay and Huizinga, 2006; Yeung and Greenwood, 2007). In general, ERG1b and ERG3 deactivate much faster than ERG1a and ERG2 (Lees-Miller et al., 1997; Hirdes et al., 2005), and there are significant species variations in $\tau_{\text {deact }}$ (Tseng, 2001). Assuming that VSN subunits form heteromeric channels, activation and deactivation will be dominated by the faster subunit(s) (Wimmers et al., 2001, 2002). In principle, differences between vomeronasal and recombinant channels could also result from processes such as phosphorylation, $\mathrm{Ca}^{2+}$ dependent channel modulation, or lipid interaction. Given the regulated coexpression of MiRP2, however, it is tempting to speculate that this pluripotent modulator of $\mathrm{K}^{+}$channels coassembles with vomeronasal ERG channels, thus altering their gating. Together, the observed channel properties are well suited to shape vomeronasal AP discharge. VSN spikes display large overshoot and last considerably longer than typical central neuron APs (Sacco et al., 2003; Ukhanov et al., 2007), providing the depolarization level and time course required for channel activation. In contrast, fast deactivation and negligible steady-state "window" current at $V_{\text {rest }}$ argue against a role in VSN resting potential maintenance.

Pheromonal information translates into specific discharge patterns. The VSN output parameter space is multidimensional [i.e., information can be encoded by discharge duration (temporal coding), frequency (rate coding), or both]. These parameters are dictated by the AP duration, shape, and associated refractory period and are thus set by the individual currents contributing to an AP. We dissected this "internal anatomy" (Bean, 2007) of basal VSN spikes using the AP clamp technique and isolated ERG currents maximally activated during the late phase of repolarization. This current deactivated with an average time constant close to the $\tau_{\text {deact }}$ value observed after step repolarization to $-60 \mathrm{mV}$. Amplitudes varied as a function of the interspike interval at frequencies $\geq 7 \mathrm{~Hz}$, showing larger currents at shorter interspike episodes. Theoretically, this could reflect channel desensitization during the initial phase $(\sim 1 \mathrm{~s})$ of spiking. However, when prerecorded APs with smaller, although increasing, intervals (55-135 $\mathrm{ms}$ ) were applied as the command voltage, amplitudes decreased with prolonged intervals throughout the recording (data not shown). We therefore conclude that, at high-frequency discharge, incomplete interspike deactivation can lead to current accumulation [similar to observations reported by Chiesa et al. (1997) and Sacco et al. (2003)]. Recently, accumulation of recombinant ERG1 and ERG3 currents was shown already during short simulated AP bursts (6 ms duration, $20 \mathrm{~ms}$ intervals) (Sturm et al., 2005). Basal VSNs display frequency saturation at $\sim 25 \mathrm{~Hz}$. Thus, minimum intervals of $\sim 40 \mathrm{~ms}$ and fast deactivation set a limit for maximum current accumulation.

How important are ERG currents for a stable input-output relationship? VSNs are remarkably sensitive to current injection, with a few picoamperes leading to repetitive firing (Liman and Corey, 1996). Yet, pheromonal stimulation can induce receptor currents of up to tens of picoamperes (this study; Inamura and Kashiwayanagi, 2000). In addition, the constricted space of the VNO lumen and putatively slow stimulus exchange likely result in a prolonged presence of pheromonal cues. Therefore, VSNs need to faithfully integrate prolonged sensory input of variable magnitude. When basal VSNs were stimulated by injection profiles that mimic endogenous receptor currents, AP output changed dramatically after ERG channel inhibition. During highamplitude current injection, VSNs frequently ceased firing after one or a few spikes. More importantly, such impaired AP discharge was similarly observed in VSNs of stimulus-deprived an- imals. Constant current injections confirmed that ERG currents provide a critical repolarizing conductance at intermediate to high stimulation levels. We thus conclude that, by ensuring repolarization sufficient to relieve $\mathrm{Na}^{+}$channels from inactivation, ERG currents extend the dynamic response range of basal VSNs.

Neurons display compensatory feedback mechanisms that reestablish a set-point functionality in response to altered sensory input. Output stability within optimal firing rate limits is achieved by modulating ion channel density, distribution, or function. Thus, de novo channel synthesis is frequently regulated to gradually restore firing properties on a longer time scale. Experimentally, compensatory feedback is frequently induced by chronic activity deprivation over a longer time scale (i.e., hours to days) (Davis, 2006). This concept provided the temporal framework for investigating the consequences of stimulus deprivation in the mouse VNO.

How can sensory input trigger changes in gene transcription? Current models propose a key role of intracellular $\mathrm{Ca}^{2+}$, a signal well correlated with neuronal activity (Turrigiano, 1999). In VSN somata, responses to pheromonal stimuli induce robust $\mathrm{Ca}^{2+}$ transients (Spehr et al., 2002; Chamero et al., 2007). $\mathrm{Ca}^{2+}$ accumulation during periods of high sensory activity or the lack of such signals during stimulus deprivation could readily control ion channel gene transcription.

In the present study, we focused on activity-dependent changes in $\mathrm{K}^{+}$channel expression because $\mathrm{K}^{+}$conductance changes have frequently been implicated in homeostatic compensation (Davis, 2006). Initially, we performed microarray analyses to achieve a genetic high-throughput. Compared with data obtained (e.g., in cancer expression profiling), we observed relatively low changes. In brain tissue microarray experiments, however, similarly low changes even for strongly regulated genes are rather the rule than the exception (Mirnics, 2001). Regulated expression is especially difficult to discern if only subpopulations of cells express the target gene (Mirnics and Pevsner, 2004). The small, although highly significant, changes we detected are therefore not surprising. Our conservative approach to data analysis (see Materials and Methods) might, however, mask further "biologically true" expression changes.

Because there is no simple quantitative correlation between gene transcription and protein translation (e.g., compare ERG2 microarray and RT-PCR data with immunochemistry results), microarray findings have to be confirmed on the protein level. Although a positive correlation between mRNA and protein levels is frequently observed, several studies have shown no or even a negative correlation, resulting from different mechanisms and pathways (with separate time constants) that independently govern transcription and translation (Lewandowski and Small, 2005). We therefore examined changes in ERGla, ERG1b, and MiRP2 expression by immunoblotting. Our results provide evidence for an effective upregulation of both ERG1 isoforms and downregulation of MiRP2 in basal VSNs. However, given that stimulation was based on chemically complex sources of social cues (both volatile and nonvolatile), it appears likely that further expression changes, beyond the scope of this study, could have occurred in both basal and apical neurons.

A key issue in interpreting our data are to resolve whether regulated gene expression is reflected in VSN physiology. We find significantly reduced ERG currents in VSNs from stimulusdeprived mice, accompanied by defects in adequate AP output in response to medium-to-high stimulation levels. Together, the combination of microarray profiling, immunoblotting, and patch-clamp recordings supports the concept that, by increasing 
ERG expression (and potentially MiRP2 downregulation) during periods of increased pheromonal stimulation, basal VSNs extend their dynamic firing range to (re)establish a meaningful sensory output.

\section{References}

Ache BW, Young JM (2005) Olfaction: diverse species, conserved principles. Neuron 48:417-430.

Barry PH (1994) JPCalc — a software package for calculating liquid junction potential corrections in patch-clamp, intracellular, epithelial and bilayer measurements and for correcting junction potential measurements. J Neurosci Methods 51:107-116.

Bean BP (2007) The action potential in mammalian central neurons. Nat Rev Neurosci 8:451-465.

Breer H, Fleischer J, Strotmann J (2006) The sense of smell: multiple olfactory subsystems. Cell Mol Life Sci 63:1465-1475.

Brennan PA, Zufall F (2006) Pheromonal communication in vertebrates. Nature 444:308-315.

Chamero P, Marton TF, Logan DW, Flanagan K, Cruz JR, Saghatelian A, Cravatt BF, Stowers L (2007) Identification of protein pheromones that promote aggressive behaviour. Nature 450:899-902.

Chiesa N, Rosati B, Arcangeli A, Olivotto M, Wanke E (1997) A novel role for HERG K+ channels: spike-frequency adaptation. J Physiol 501:313-318.

Curran ME, Splawski I, Timothy KW, Vincent GM, Green ED, Keating MT (1995) A molecular basis for cardiac arrhythmia: HERG mutations cause long QT syndrome. Cell 80:795-803.

Davis GW (2006) Homeostatic control of neural activity: from phenomenology to molecular design. Annu Rev Neurosci 29:307-323.

Firestein S (2001) How the olfactory system makes sense of scents. Nature 413:211-218.

Furlan F, Taccola G, Grandolfo M, Guasti L, Arcangeli A, Nistri A, Ballerini L (2007) ERG conductance expression modulates the excitability of ventral horn GABAergic interneurons that control rhythmic oscillations in the developing mouse spinal cord. J Neurosci 27:919-928.

Guasti L, Cilia E, Crociani O, Hofmann G, Polvani S, Becchetti A, Wanke E, Tempia F, Arcangeli A (2005) Expression pattern of the ether-a-go-gorelated (ERG) family proteins in the adult mouse central nervous system: evidence for coassembly of different subunits. J Comp Neurol 491:157-174.

Gurrola GB, Rosati B, Rocchetti M, Pimienta G, Zaza A, Arcangeli A, Olivotto M, Possani LD, Wanke E (1999) A toxin to nervous, cardiac, and endocrine ERG K+ channels isolated from Centruroides noxius scorpion venom. FASEB J 13:953-962.

Halpern M, Martinez-Marcos A (2003) Structure and function of the vomeronasal system: an update. Prog Neurobiol 70:245-318.

Hirdes W, Horowitz LF, Hille B (2004) Muscarinic modulation of erg potassium current. J Physiol 559:67-84.

Hirdes W, Schweizer M, Schuricht KS, Guddat SS, Wulfsen I, Bauer CK, Schwarz JR (2005) Fast erg K+ currents in rat embryonic serotonergic neurones. J Physiol 564:33-49.

Inamura K, Kashiwayanagi M (2000) Inward current responses to urinary substances in rat vomeronasal sensory neurons. Eur J Neurosci 12:3529-3536.

Kelliher KR, Spehr M, Li XH, Zufall F, Leinders-Zufall T (2006) Pheromonal recognition memory induced by TRPC2-independent vomeronasal sensing. Eur J Neurosci 23:3385-3390.

Kimoto H, Haga S, Sato K, Touhara K (2005) Sex-specific peptides from exocrine glands stimulate mouse vomeronasal sensory neurons. Nature 437:898-901.

Korolkova YV, Kozlov SA, Lipkin AV, Pluzhnikov KA, Hadley JK, Filippov AK, Brown DA, Angelo K, Strobaek D, Jespersen T, Olesen SP, Jensen BS, Grishin EV (2001) An ERG channel inhibitor from the scorpion Buthus eupeus. J Biol Chem 276:9868-9876.

Lau YE, Cherry JA (2000) Distribution of PDE4a and $\mathrm{G}_{\mathrm{o}}$ alpha immunoreactivity in the accessory olfactory system of the mouse. Neuroreport 11:27-32.

Lees-Miller JP, Kondo C, Wang L, Duff HJ (1997) Electrophysiological characterization of an alternatively processed ERG $\mathrm{K}+$ channel in mouse and human hearts. Circ Res 81:719-726.

Leinders-Zufall T, Lane AP, Puche AC, Ma W, Novotny MV, Shipley MT,
Zufall F (2000) Ultrasensitive pheromone detection by mammalian vomeronasal neurons. Nature 405:792-796.

Leinders-Zufall T, Brennan P, Widmayer P, PC S, Maul-Pavicic A, Jager M, Li $\mathrm{XH}$, Breer H, Zufall F, Boehm T (2004) MHC class I peptides as chemosensory signals in the vomeronasal organ. Science 306:1033-1037.

Lewandowski NM, Small SA (2005) Brain microarray: finding needles in molecular haystacks. J Neurosci 25:10341-10346.

Liman ER, Corey DP (1996) Electrophysiological characterization of chemosensory neurons from the mouse vomeronasal organ. J Neurosci $16: 4625-4637$

London B, Trudeau MC, Newton KP, Beyer AK, Copeland NG, Gilbert DJ, Jenkins NA, Satler CA, Robertson GA (1997) Two isoforms of the mouse ether-a-go-go-related gene coassemble to form channels with properties similar to the rapidly activating component of the cardiac delayed rectifier K+ current. Circ Res 81:870-878.

Martini S, Silvotti L, Shirazi A, Ryba NJ, Tirindelli R (2001) Co-expression of putative pheromone receptors in the sensory neurons of the vomeronasal organ. J Neurosci 21:843-848.

McCrossan ZA, Lewis A, Panaghie G, Jordan PN, Christini DJ, Lerner DJ, Abbott GW (2003) MinK-related peptide 2 modulates Kv2.1 and Kv3.1 potassium channels in mammalian brain. J Neurosci 23:8077-8091.

McKay CM, Huizinga JD (2006) Muscarinic regulation of ether-a-go-gorelated gene $\mathrm{K}+$ currents in interstitial cells of Cajal. J Pharmacol Exp Ther 319:1112-1123.

Mirnics K (2001) Microarrays in brain research: the good, the bad and the ugly. Nat Rev Neurosci 2:444-447.

Mirnics K, Pevsner J (2004) Progress in the use of microarray technology to study the neurobiology of disease. Nat Neurosci 7:434-439.

Mombaerts P (2004) Genes and ligands for odorant, vomeronasal and taste receptors. Nat Rev Neurosci 5:263-278.

Nerbonne JM, Kass RS (2005) Molecular physiology of cardiac repolarization. Physiol Rev 85:1205-1253.

Nerbonne JM, Nichols CG, Schwarz TL, Escande D (2001) Genetic manipulation of cardiac $\mathrm{K}(+)$ channel function in mice: what have we learned, and where do we go from here? Circ Res 89:944-956.

Nodari F, Hsu FF, Fu X, Holekamp TF, Kao LF, Turk J, Holy TE (2008) Sulfated steroids as natural ligands of mouse pheromone-sensing neurons. J Neurosci 28:6407-6418.

Papa M, Boscia F, Canitano A, Castaldo P, Sellitti S, Annunziato L, Taglialatela M (2003) Expression pattern of the ether-a-gogo-related (ERG) K+ channel-encoding genes ERG1, ERG2, and ERG3 in the adult rat central nervous system. J Comp Neurol 466:119-135.

Pond AL, Nerbonne JM (2001) ERG proteins and functional cardiac I(Kr) channels in rat, mouse, and human heart. Trends Cardiovasc Med 11:286-294.

Pond AL, Scheve BK, Benedict AT, Petrecca K, Van Wagoner DR, Shrier A, Nerbonne JM (2000) Expression of distinct ERG proteins in rat, mouse, and human heart. Relation to functional $\mathrm{I}(\mathrm{Kr})$ channels. J Biol Chem 275:5997-6006.

Potter SM, Zheng C, Koos DS, Feinstein P, Fraser SE, Mombaerts P (2001) Structure and emergence of specific olfactory glomeruli in the mouse. J Neurosci 21:9713-9723.

Restano-Cassulini R, Korolkova YV, Diochot S, Gurrola G, Guasti L, Possani LD, Lazdunski M, Grishin EV, Arcangeli A, Wanke E (2006) Species diversity and peptide toxins blocking selectivity of ether-a-go-go-related gene subfamily $\mathrm{K}+$ channels in the central nervous system. Mol Pharmacol 69:1673-1683.

Restrepo D, Lin W, Salcedo E, Yamazaki K, Beauchamp G (2006) Odortypes and MHC peptides: complementary chemosignals of MHC haplotype? Trends Neurosci 29:604-609.

Rodriguez I (2004) Pheromone receptors in mammals. Horm Behav $46: 219-230$.

Sacco T, Bruno A, Wanke E, Tempia F (2003) Functional roles of an ERG current isolated in cerebellar Purkinje neurons. J Neurophysiol 90:1817-1828.

Salama G, London B (2007) Mouse models of long QT syndrome. J Physiol 578:43-53.

Sanguinetti MC, Jiang C, Curran ME, Keating MT (1995) A mechanistic link between an inherited and an acquired cardiac arrhythmia: HERG encodes the IKr potassium channel. Cell 81:299-307.

Sanguinetti MC, Tristani-Firouzi M (2006) hERG potassium channels and cardiac arrhythmia. Nature 440:463-469. 
Schonherr R, Rosati B, Hehl S, Rao VG, Arcangeli A, Olivotto M, Heinemann SH, Wanke E (1999) Functional role of the slow activation property of ERG K+ channels. Eur J Neurosci 11:753-760.

Schroeder BC, Waldegger S, Fehr S, Bleich M, Warth R, Greger R, Jentsch TJ (2000) A constitutively open potassium channel formed by KCNQ1 and KCNE3. Nature 403:196-199.

Schwarz JR, Bauer CK (2004) Functions of erg K+ channels in excitable cells. J Cell Mol Med 8:22-30.

Shi W, Wymore RS, Wang HS, Pan Z, Cohen IS, McKinnon D, Dixon JE (1997) Identification of two nervous system-specific members of the erg potassium channel gene family. J Neurosci 17:9423-9432.

Spector PS, Curran ME, Keating MT, Sanguinetti MC (1996) Class III antiarrhythmic drugs block HERG, a human cardiac delayed rectifier $\mathrm{K}+$ channel. Open-channel block by methanesulfonanilides. Circ Res 78:499-503.

Spehr M, Hatt H, Wetzel CH (2002) Arachidonic acid plays a role in rat vomeronasal signal transduction. J Neurosci 22:8429-8437.

Spehr M, Kelliher KR, Li XH, Boehm T, Leinders-Zufall T, Zufall F (2006) Essential role of the main olfactory system in social recognition of major histocompatibility complex peptide ligands. J Neurosci 26:1961-1970.

Sturm P, Wimmers S, Schwarz JR, Bauer CK (2005) Extracellular potassium effects are conserved within the rat erg $\mathrm{K}+$ channel family. J Physiol $564: 329-345$.

Tseng GN (2001) I(Kr): the hERG channel. J Mol Cell Cardiol 33:835-849. Turrigiano GG (1999) Homeostatic plasticity in neuronal networks: the more things change, the more they stay the same. Trends Neurosci 22:221-227.

Ukhanov K, Leinders-Zufall T, Zufall F (2007) Patch-clamp analysis of gene-targeted vomeronasal neurons expressing a defined V1r or V2r receptor: ionic mechanisms underlying persistent firing. J Neurophysiol 98:2357-2369.

Warmke JW, Ganetzky B (1994) A family of potassium channel genes related to eag in Drosophila and mammals. Proc Natl Acad Sci U S A 91:3438-3442.

West AE, Chen WG, Dalva MB, Dolmetsch RE, Kornhauser JM, Shaywitz AJ, Takasu MA, Tao X, Greenberg ME (2001) Calcium regulation of neuronal gene expression. Proc Natl Acad Sci U S A 98:11024-11031.

Wimmers S, Wulfsen I, Bauer CK, Schwarz JR (2001) Erg1, erg2 and erg3 K channel subunits are able to form heteromultimers. Pflugers Arch 441:450-455.

Wimmers S, Bauer CK, Schwarz JR (2002) Biophysical properties of heteromultimeric erg K+ channels. Pflugers Arch 445:423-430.

Yeung SY, Greenwood IA (2007) Pharmacological and biophysical isolation of $\mathrm{K}+$ currents encoded by ether-a-go-go-related genes in murine hepatic portal vein smooth muscle cells. Am J Physiol Cell Physiol 292:C468-C476.

Zhang W, Linden DJ (2003) The other side of the engram: experiencedriven changes in neuronal intrinsic excitability. Nat Rev Neurosci 4:885-900.

Zufall F, Munger SD (2001) From odor and pheromone transduction to the organization of the sense of smell. Trends Neurosci 24:191-193. 